\title{
Traditional landscape and rural development: comparative study in three terraced areas in northern, central and southern Italy to evaluate the efficacy of GAEC standard 4.4 of cross compliance
}

\author{
Mauro Agnoletti, ${ }^{1}$ Giovanni Cargnello, ${ }^{2}$ Lorenzo Gardin, ${ }^{3}$ Antonio Santoro, ${ }^{1}$ \\ Paolo Bazzoffi, ${ }^{4}$ Luigi Sansone, ${ }^{2}$ Luciano Pezza, ${ }^{2}$ Nicola Belfiore ${ }^{2}$ \\ ${ }^{1}$ DEISTAF - Laboratory for Landscape and Cultural Heritage, Agriculture Faculty, University \\ of Florence; ${ }^{2}$ CRA-VIT Agricultural Research Council, Viticulture Research Centre, Conegliano \\ Veneto; ${ }^{3}$ Forestry, freelancer, Firenze; ${ }^{4}$ CRA-ABP Agricultural Research Council, Agrobiology and \\ Pedology Research Centre, Firenze, Italy
}

\begin{abstract}
The recent National Strategic Plan 2007-2013 has introduced landscape as a strategic objective of the rural sector. This represents a minor revolution in the way of visualizing the role of the landscape, together with that of agriculture and the rural territory as a whole, and demonstrates the importance of treating the landscape with a systematic point of view. As part of the Efficond project, three sample areas have been identified, each of about 800-1000 hectares, in zones with important historical - cultural landscapes that are included in the National Catalogue of Historical Rural Landscapes. For each sample area a methodology has been applied, defined Historical Cultural Evaluation Approach, developed as part of a project for the monitoring of the Tuscan landscape that we have simplified and adapted. This methodology is based on the consideration that the landscape is the result of the centuries-old interac-
\end{abstract}

Correspondence: Lorenzo Gardin, via Guerrazzi 2rosso, 50132 Firenze, Italy. Tel. +39.055.5398582. E-mail: lorenzo@studiogardin.it

Key words: historical landscape, land use dynamics, terraces.

Contribution: MA, methodology developing and application; GC, LS, CRA-VIT scientific coordination; LG, AS, scientific and technical framework, selection of sample areas, choice of the methodology to be applied, environment and landscape description, establishment of a georeferenced database for each area, choice of images and informative layers, photo-interpretation of land use and characterization of terraced areas, data processing and indices of landscape ecology, analysis of results and comment, writing the text, bibliographic research; $\mathrm{PB}$, research supervisor and guidance, as leader of the EFFICOND project; LP, NB, technical work assistance.

Received for publication: 25 March 2011.

Accepted for publication: 18 May 2011.

(C) Copyright M. Agnoletti et al., 2011

Under no circumstances figures can be used without prior written consent of the copyright owner.

Licensee PAGEPress, Italy

Italian Journal of Agronomy 2011; 6(s1):e16

doi:10.4081/ija.2011.6.s1.e16

This work is licensed under a Creative Commons Attribution NonCommercial 3.0 License (CC BY-NC 3.0). tion between man and the environment, and so to define an element of the landscape as characteristic it is necessary to evaluate the land use dynamics and landscape changes that took place in the past, identifying those that have persisted for a long time, are slowly evolving or stabilized. The study of the historical landscape, which in the proposed methodology refers to the 50's, has been done through the interpretation and analysis of aerial photographs taken on the GAI flight in 1954, and has allowed the characteristic, traditional and historical elements of that landscape to be identified and an insight to be gained into the cultural identity of the area. Through the creation of specific indices of density and intensity of the terracing obtained by photo-interpretation, field surveys and GIS elaborations, it was possible to classify the sample areas for this specific and important landscape element, compare the results in two periods and evaluate their frequency in the territory. Multi-temporal comparative analysis is being used increasingly often, especially for the study of territories of value, and in our case has been accompanied both by mapping of the landscape dynamics, which identifies the areas subject to transformations in the considered period, and by tables and figures that allow the evolution of a unit of land use to be followed, observing how this has evolved over time. The evaluation of these evolutionary dynamics has then been integrated with a set of indices, in part borrowed from landscape ecology, and in part specifically developed for areas historically shaped by man, which demonstrate that the landscape has become less fragmented and that the layout of fields has been adapted to a different agricultural model that has profoundly changed the structure of the traditional landscape. The efficacy of the laws protecting the characteristic elements of the landscape is strictly linked to the maintenance of its diversity and typicality and conservation of the complexity of the landscape mosaic. Its evaluation necessitates a historical analysis of the evolutionary dynamics conducted at a purely local level.

\section{Introduction}

This paper reports the results obtained within the domain of the CRA EFFICOND ${ }^{1}$ project, set up to meet the specific need of the National

${ }^{I}$ EFFICOND $=($ EFF $=$ Effectiveness of environmental standards, $C O N D=$ Cross compliance $)$ is a CRA (Agricultural Research Council) project started in 2009 to meet the specific need of NRN (National Rural Network) to monitor and evaluate the effectiveness of environmental protection actions mandated by the CAP to national agricultural policy and implemented by the Regional Rural Development Plans (RDP). The main project objectives are the evaluation of GAEC standards implemented under cross compliance and the development of agri-environmental indicators for nation-wide scenario analysis. The EFFICOND project involves 10 operational units with experimental fields located throughout the country. 
Rural Network to monitor and evaluate the actions of environmental conservation devolved by the CAP to national agricultural policy and implemented by the Regional Rural Development Plans. The project proposes the development of agro-environmental indicators for the mid-term evaluation of the cross compliance rules; it involves 54 researchers from 4 departments organized in 10 research centres and units, with experimental fields distributed throughout Italy.

The evaluation of the efficacy of the cross compliance rules, through an analysis of the preliminary results of some case studies, is published in response to a specific appeal to focus attention on the subject and encourage a better understanding of it.

The cross compliance (D.M. 22 December 2009) includes for Objective 4 - Minimum level of maintenance: to ensure a minimum level of maintenance and avoid deterioration of the habitat, the standard 4.4: Maintenance of the characteristic elements of the landscape, including hedges, ponds, ditches, isolated trees or in rows or groups and field margins which prohibits the elimination of existing terraces, demarcated by a dry-stone wall or grassed escarpment, or any unauthorized levelling, observance of the regional measures adopted according to Directive 79/409/EEC and Directive 92/43/EEC and observance of the regional measures of protection of the characteristic elements of the landscape not included in letter $\mathrm{c}$ ).

\section{State-of-the-art}

The European Landscape Convention, signed in Florence in 2000 but only coming into effect in Italy in 2006, is an essential point of reference for the landscape that, in art. 1, is defined as an area, as perceived by people, whose character is the result of the action and interaction of natural and/or human factors. This widens the conceptual frontiers of landscape, often otherwise considered only as the set of natural characteristics of a place, or only in its aesthetic dimension, and evaluated from those points of view.

The Convention commits the member states to formulate policies to preserve, manage and plan the landscape. As a consequence of these indications, the recent National Strategic Plan for Rural Development 2007-2013 has introduced the landscape as a strategic objective of the agricultural policies. This has represented a minor revolution in the way of visualizing the role of the landscape, together with that of agriculture and the rural territory as a whole, also because up to now little has been done in Italy for the rural landscape, demonstrating the importance of treating it with a systematic point of view (Agnoletti, 2006) at superordinate planning level.

In Italy, the study of the landscape has been influenced by two principal schools of thought, the first regarding the historical approach, the second the ecological approach (Agnoletti, 2002). The studies of Biasutti and Sestini in the 1950's paid greatest attention to the geomorphological, climatic, vegetational factors etc., which were followed by the studies of Lucio Gambi and Emilio Sereni in the 1960's (Baldeschi, 2005). The ecological aspect was anyway prevalent towards the end of the century (Ingegnoli, 1993; Pignatti, 1994; Farina, 2001), also in the planning sector (Romani, 1994), while the importance of the historical factor appears to have re-emerged in some more recent planning approaches (Magnaghi, 2005). Placing the actions of man in harmony with the natural processes and identifying this as one of the elements of the landscape has been the principal strategy of Ecological Planning, the most prevalent scientific approach in planning at world level in the last decades of the $20^{\text {th }}$ century, with few attempts to place culture as the central element (Mc Harg, 2007).

For this reason, for the study of the rural territory, profoundly marked by human impacts, but often subject to interpretations that invariably relegate man to being a factor of degradation or disturbance, it is useful to utilize analysis methods that can better encompass the significance and role of the historical-cultural factors, also in relation to the measurement of biodiversity, which is almost always tailored to natural systems, but lit- tle suited to the biodiversity produced by the human systems.

Only in a sufficiently long time-frame is it possible to identify the importance of the various historical stratifications and understand what may be considered a characteristic, i.e. identifying, element, individuating the emergencies, the characteristics of vulnerability and fragility of the system.

The landscape changes in Italy during the last century represent a general reduction in the landscape diversity, linked to the loss of complex land uses, with a substantial homogenization of the landscape mosaic caused by the industrialization of agriculture and the expansion of woodland and scrub at the expense of crops or abandoned pastures (Agnoletti, 2010; Ingegnoli, 1993; Baudry and Burel, 1982; Vos and Stortelder, 1992). The loss of diversity is well expressed by the data gathered with a landscape monitoring system that analyzed $1 \%$ of the Tuscan territory on thirteen study areas, demonstrating a loss of habitat diversity linked to land uses of around $45 \%$ in the last two centuries (Agnoletti et al., 2006). All this has endangered the uniqueness of the Italian rural landscape and compromised the possibility of it being exploited as an added value for the development of the rural territory.

The Italian Ministry of Agricultural Food and Forestry Policies has recently conducted a survey for the compilation of a National Catalogue of Historical Rural Landscapes (Agnoletti, 2010), with the aim of ascertaining the conservation status of this resource and developing adequate policies for its enhancement. The landscapes inventoried for the catalogue are distributed over a wide range of environmental and socioeconomic situations, with great aesthetic appeal, significant potential from the point of view of economic development and of enormous value for biodiversity and the quality of life of the local populations. These are landscapes characterized by agricultural crops and pastoral and forestry elements, but also human settlements, which represent a fundamental element of the cultural identity of the area, as they are testimony to a millenary adaptation of man's activities to an often hostile environment. The areas surveyed are an important starting point for the setting up of instruments of monitoring, conservation and upgrading within the ambits of rural development planning.

The study demonstrates that the quality of the landscape in southern and central areas is high, especially in those areas spared from the encroachment of urban areas and industrialization and from phenomena of crop intensification and abandoning, which have involved a drastic reduction of the traditional landscapes, defined as those landscapes that have been present in a given territory for a long time (even many centuries) and are stabilized or slowly evolving.

\section{Materials and Methods}

\section{Case studies in the Efficond project}

Three case studies were identified, composed of sample areas of about 800-1000 ha each. In order to have a national distribution, they are located in northern, central and southern Italy and lie in districts with significant historical - cultural landscapes that form part of the areas included in the Catalogue of Historical Rural Landscapes (Agnoletti, 2010). For each sample area a methodology was applied, defined Historical Cultural Evaluation Approach, developed as part of a project for the monitoring of the Tuscan landscape (Agnoletti, 2010), which we simplified and adapted. This methodology is based on the consideration that the landscape is the result of the centuries-old interaction between man and the environment, and so to define an element of the landscape as characteristic the land use dynamics and changes to the landscape must be evaluated over a long time span. The analyses in Tuscany considered three dates starting from the early $19^{\text {th }}$ century, but in our case, to simplify the analysis by making the data homogeneous and comparable, we adopted as year zero the landscape in the 
1950s, representative of a socio-economic situation still linked to traditional farming, comparing this with today's land use evaluated using orthophotos taken in 2007.

The study of the historical landscape, done through the analysis of aerial photos taken on the GAI flight in 1954, allows the characteristic, traditional and historical elements of that landscape to be identified and to gain an insight into the cultural identity of the study area.

A comparative analysis of the evolution of the landscape, conducted by means of map overlays, cross tabulation and specific evaluation indices, has demonstrated that the changes caused by the progressive disappearance of characteristic elements, like types of crops, terracing and linear elements (hedges, rows of trees, stone walls, etc.), involve degradation of the landscape, also in the most strictly ecological sense. The analysis therefore demonstrates the value of maintaining the characteristic elements of the landscape, with the additional aim of protecting biodiversity.

The 1954 photos were digitalized and imported into a GIS together with the other available information and georeferenced on the basis of the orthophotos of 2007. The images on the two dates, despite the different resolutions and the effect of distortion on the photos of 1954, resulted as being sufficiently coincident, with the conspicuous points selected on the aerial photos (historical buildings, roads, trigonometric points, etc.) on the two dates having an entirely acceptable mean error of 5 metres, which facilitated the operations of retrieval and topological overlay.

The first step for each sample area was the stereoscopic photo-interpretation of the aerial photos of 1954 and a video photo-interpretation of the orthophotos of 2007, aimed at identifying types of land use and elements that have an important significance for the rural landscape (stone walls, terraces, hedges, tree rows, ponds, etc.). The list of land uses classification is reported in Table 1.

While the resolution of the 2007 orthophotos was suitable for the purpose, the same cannot be said for the aerial photos of 1954, which, having been taken at a higher altitude and being generally of lower quality, did not always provide the required level of detail. The simplification and pooling of some classes utilized in the land use map therefore became necessary to be able to do the overlays for the definition of the evolutionary dynamics. In addition, it was not always possible to distinguish all the types and their level of density, for example between arable crops and mowed meadows in 1954, or between sparse and degraded woodlands, therefore shrub-like, and true scrublands. The result of the digitalization of the land use on the two dates was checked against the topology to eliminate possible overlapping micro-areas, and zones having both an area major of 10 square meters.

In the first instance the investigation was concentrated on terraces, given that they have high landscape value, are widespread throughout the peninsula and play a key role in production, biodiversity and the hydro-geological system. In order to precisely characterize a terraced landscape and identify some of its parameters that may be reproduced and compared in other geographical contexts, where the quality if the 1954 aerial photos made it possible, the mapping and classification methodology used in the ALPTER Project (Scaramellini, 2008) was applied. In some cases the 1954 photos did not contain sufficient detail for the analysis, in others the terracing was so dense that the whole terraced area would have been classified in the same way. After having photo-interpreted and digitalized the terraces present in the landscape on the two dates, their presence was considered in relation to a homogeneous surface area, elaborating the following quantitative ratios.

The index of extension of the terracing was derived from the calculation of the density of the terraced polygons on a hexagonal template with an area of 10,000 square metres (1 hectare), accomplished using the Repeating shapes extension for ArcGIS (Jenness, 2006). The sample area was analyzed reinstating the terraced area value within each hexagon. The maximum reachable value is, naturally, one, i.e. 1 hectare of terraced area per hectare of land. The analysis results were grouped in density classes, with the follow classification (Scaramellini, 2008):

- microterraced landscape: $0.01-0.33 \mathrm{~m}^{2} / \mathrm{m}^{2}$;

- mesoterraced landscape: $0.33-0.66 \mathrm{~m}^{2} / \mathrm{m}^{2}$;

- macroterraced landscape: $0.66-1.00 \mathrm{~m}^{2} / \mathrm{m}^{2}$.

The index of intensity of the terracing was then calculated as the ratio between vertical lines of the terraced system and the horizontal surfaces, expressed as linear metres of dry-stone wall (the edge of the terraces) referred to the unit area of 1 hectare. This operation allowed the linear datum to be elaborated as a parameter of surface area and to obtain spatial elements (the reference hexagons) that can be compared with the other information in the database. In general terms, the higher is the value of the density, the further is the distance from the original morphology and the greater is the need for management of the territory; the higher is the density, the greater is also the potential fragility of that part of the terraced system, especially in the case of no or reduced maintenance. This index was expressed in linear metres per hectare, defining the following 3 classes:

- low intensity: 5-200 m/ha

- average intensity: $200-800 \mathrm{~m} / \mathrm{ha}$;

- high intensity: $>800 \mathrm{~m} / \mathrm{ha}$.

Combining the classes of density and intensity, it was possible to classify the terraced systems in 9 potential classes, which follow a gradient of increasing human impact on the territory, identifying areas from microterraced at low intensity to areas macroterraced at high intensity.

Some indices taken from landscape ecology have also been applied

Table 1. List of land uses utilized in image interpretation.

\begin{tabular}{|c|c|}
\hline Code & Description \\
\hline 1 & Urban areas, anthropic \\
\hline 10 & Horticulture \\
\hline 11 & Broadleaved woodlands \\
\hline 13 & Conifer woodlands \\
\hline 14 & Mixed woodlands \\
\hline 15 & Reforestation \\
\hline 18 & Scrub areas in evolution \\
\hline 20 & Area with scattered vegetation \\
\hline $2 \mathrm{~A}$ & Arable crops \\
\hline $2 \mathrm{~B}$ & Treed arable crops \\
\hline 4 & Vineyard \\
\hline $4 \mathrm{~A}$ & Contour-planted vineyard \\
\hline $4 \mathrm{~B}$ & Longitudinal vineyard \\
\hline 5 & Orchard \\
\hline $6 \mathrm{~A}$ & Olive grove with regular layout \\
\hline $6 \mathrm{~B}$ & Olive grove with irregular layout \\
\hline $6 \mathrm{C}$ & Olive grove with vineyard \\
\hline 7 & Meadows \\
\hline $8 \mathrm{~A}$ & Bare pasture \\
\hline $8 \mathrm{~B}$ & Treed pasture \\
\hline $9 \mathrm{~A}$ & Arable crops with olive trees \\
\hline $9 \mathrm{~B}$ & Arable crops with vines \\
\hline $9 \mathrm{C}$ & Arable crops with olive trees and vines \\
\hline 9D & Uncultivated grassland \\
\hline ACQ & Waters \\
\hline $\mathrm{R}$ & Rocky outcrops \\
\hline ST & Roads \\
\hline
\end{tabular}


for evaluating the changes in landscape structure. In addition to number of land uses, number of patches and average area of patches, we have applied Shannon's Index of Dominance, Hill's Diversity Number and Sharpe's Index (Agnoletti, 2007).

- Shannon's Index of Dominance helps to evaluate the degree of landscape complexity and fragmentation, as it is based on the variation of dimensional relationships of the land use classes. If the Index grows there is an increase of the dominance of some landscape patches on the others, resulting in a decrease of the complexity of the analyzed landscape mosaic, because the landscape is dominated by fewer types of land use.

- Hill's Diversity Number actually expresses the effective number of land uses that contribute to the diversity of a particular landscape.

- Sharpe's Index highlights the significance of certain processes with regard to land use changes that have lapsed in a given historical period. This index is applied to each type of land use and it can assume a positive or a negative value, depending on the surface increase or decrease of that particular land use. The value of the index is not directly linked to the variations in terms of hectares, but it shows the land uses who are most responsible for landscape changes in a certain period.

In addition to landscape ecology indices, was also applied an Historical Index (Agnoletti, 2007), based on time persistence and on surface diffusion, that allows the creation of a ranking of land use, according to the values of the index, so that it is possible to identify the landscape emergencies, which are formed by the land uses that have a higher risk of disappearing from the landscape mosaic. The values of Historical Index can be used to create maps for identifying the areas that have preserved the historical land uses and landscape structure, and the areas that have an higher risk of disappearance of certain land uses.

\section{Lamole study area - Greve in Chianti, Florence}

The Lamole study area covers 700.82 hectares, and is situated in the municipality of Greve in Chianti, in the province of Florence. The hamlet of Lamole is in the southern part of the territory, and the centre of the study area lies approximately 580 metres a.s.l. The area is privately owned. The geological substrate of the area is formed mainly by turbidite quartzose (42\%)-feldspathic (27\%) sandstones, with calcite (7\%), phyllosilicates (24\%) and silty schists, while in the south there are friable yellow and grey marls of Oligocene origin.

\section{The landscape in 1954}

Analysis of the aerial photos shows that in 1954 the landscape was dominated by woodland (Figures 1 and 2), which covered more than half of the area (58\%), followed by various types of farmland (36\%), anthropic areas (5\%), meadows and pastures (1\%). Most of the wooded areas are classified as broadleaved woodlands ( $46 \%$ of the total), but there are also mixed (2.5\%) and conifer woodlands (1.6\%); there is also a significant amount of scrub formations (7.1\%) (Table 2). The agricultural landscape appears to be more fragmented than the forestry one. The best represented land use class is that of olive groves in monoculture ( $16 \%$ of the study area), mainly olive groves with irregular layout, of which there are about 99 hectares, against the 11.3 hectares of olive groves with regular layout. Specialized vineyards are instead not typical of the landscape ( $1 \%$ of the total area), in that vines were mainly grown in inter-cropping. Indeed, the agricultural land use type that most characterizes the Lamole landscape in the 1950's is inter-cropping, with six types identified, the most common of which is arable crops with olive trees and vines (5.5\% of the entire area). Land growing arable crops covers $7 \%$ of the study area (20\% of the farmland). Pastures and meadows are instead of limited landscape or historical-cultural importance, given that livestock rearing had a decidedly marginal role among farming activities in Lamole.

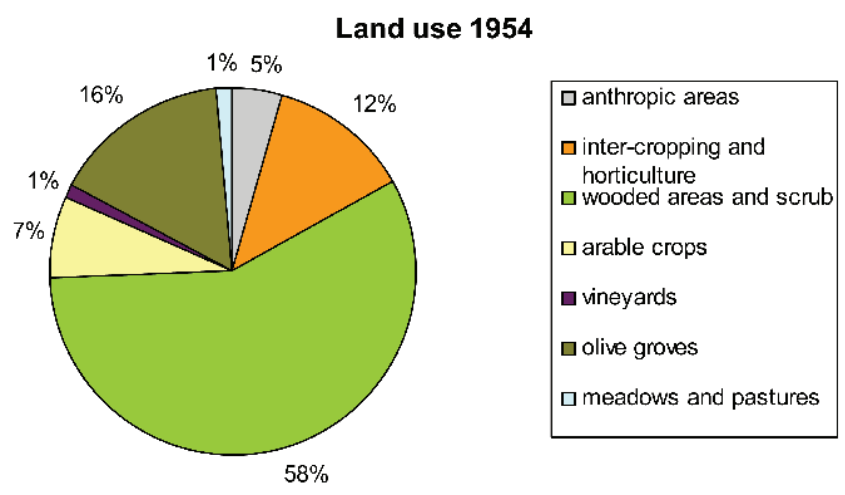

Figure 1. Percentages of land use cover for 1954 in the Lamole study area.

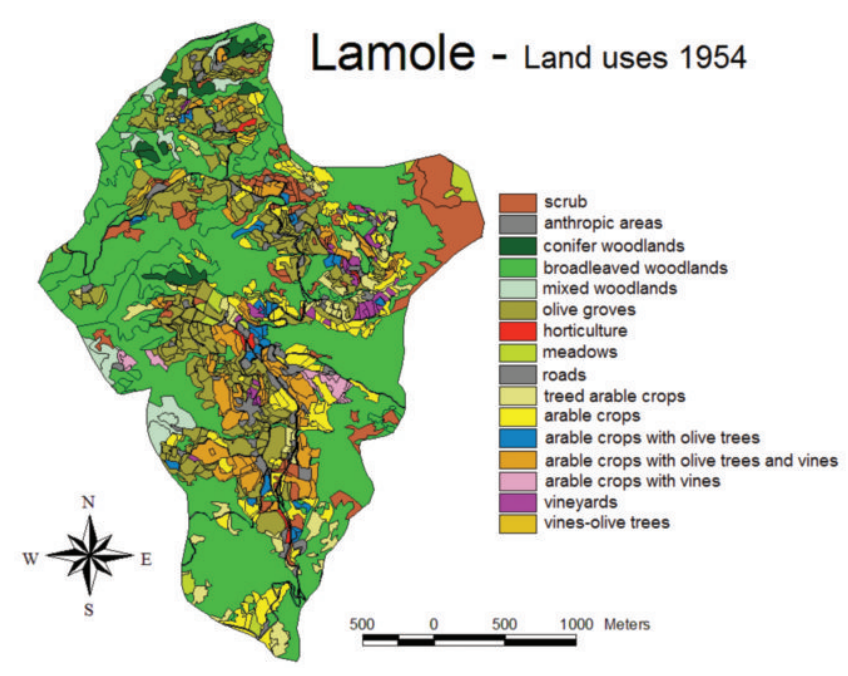

Figure 2. Map of the land uses in 1954 (Lamole study area).

Table 2. Land use classification for 1954 in the Lamole study area.

\begin{tabular}{lrr} 
Land use 1954 & Area (ha) & $\%$ \\
Anthropic areas & 21.70 & 3.10 \\
Horticulture & 2.33 & 0.33 \\
\hline Broadleaved woodlands & 324.97 & 46.37 \\
Conifer woodlands & 11.19 & 1.60 \\
\hline Mixed woodlands & 17.64 & 2.52 \\
Scrub & 49.54 & 7.07 \\
\hline Arable crops & 50.08 & 7.15 \\
Treed arable crops & 27.84 & 3.97 \\
\hline Contoured vineyards & 6.96 & 0.99 \\
Longitudinal vineyards & 1.14 & 0.16 \\
\hline Olive grove with regular layout & 11.36 & 1.62 \\
Olive grove with irregular layout & 98.91 & 14.11 \\
\hline Vines-olive trees & 2.54 & 0.36 \\
Meadows & 8.07 & 1.15 \\
\hline Treed pastures & 2.08 & 0.30 \\
Arable crops with olive trees & 9.38 & 1.34 \\
\hline Arable crops with vines & 5.97 & 0.85 \\
Arable crops with olive trees and vines & 38.72 & 5.52 \\
\hline Roads & 10.38 & 1.48 \\
Total & 700.81 & 100.00 \\
\hline
\end{tabular}


Today's landscape

Today (Figure 3, 4 and 5; Table 3), the Lamole landscape continues to be dominated by woodlands, which cover $69 \%$ of the territory. These are followed by agricultural areas (26\%) and anthropic areas (5\%), while pastures and meadows remain very limited (less than 1\%). Within the wooded areas, broadleaved woodland is still the main class of land use, covering $50.3 \%$ of the entire surface area, followed by mixed woodland (7.2\%), conifer woodland (6.3\%) and scrub (4.5\%); there is also sporadic reforestation, limited to little more than one hectare. Farming remains the main production nucleus of Lamole, and specialized vineyards have become the most widespread class of agricultural land use (on 14\% of the study area), overtaking olive groves that are reduced to $5 \%$. The local landscape still conserves a few significant areas of traditional inter-cropping, especially as regards the mix between arable crops and vines (1.4\% of the area). Arable crops, both simple and treed, have seen a marked reduction in surface area over the past fifty years, but being on $1.3 \%$ and $1.9 \%$ of the study area respectively, they are still an important landscape spatial component. The land occupied by anthropic areas has remained practically unvaried since 1954, while meadows and pastures continue to play a marginal role in the local landscape mosaic.

\section{Landscape changes in the period 1954-2007}

The first piece of information that emerges from the overlaying of the data relating to the landscapes in 1954 and 2007 is that there has been no land use change on approximately $70 \%$ of the analyzed territory (Figure 6). The most significant dynamic is the expansion of woodland areas (14\%), followed by intensification (9\%), extensification (3\%) and deforestation (3\%), while urbanization is very limited in terms of surface area involved (1\%).

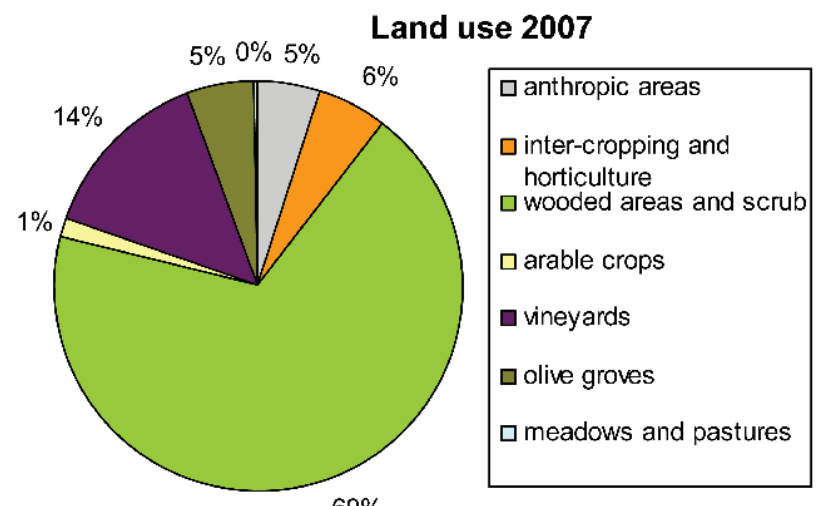

$69 \%$

Figure 3. Percentages of land use cover for 2007 (Lamole study area).

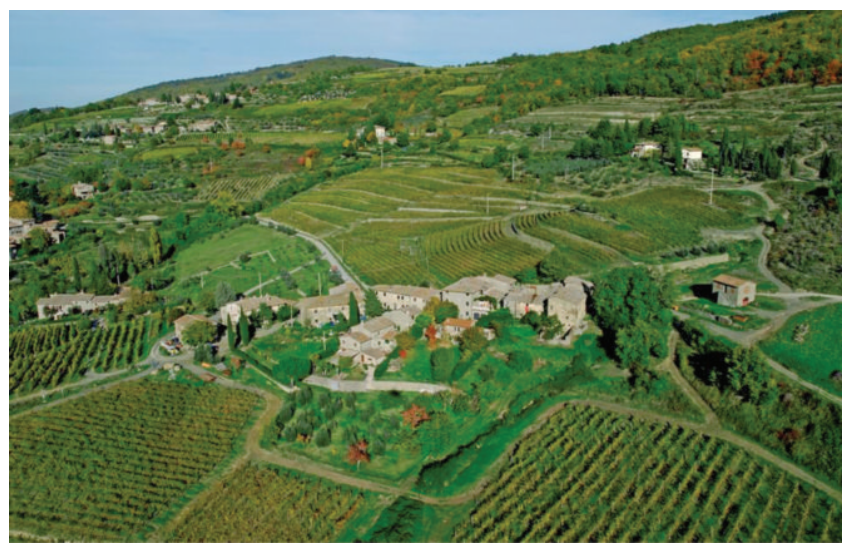

Figure 4. Today's landscape (Lamole study area).

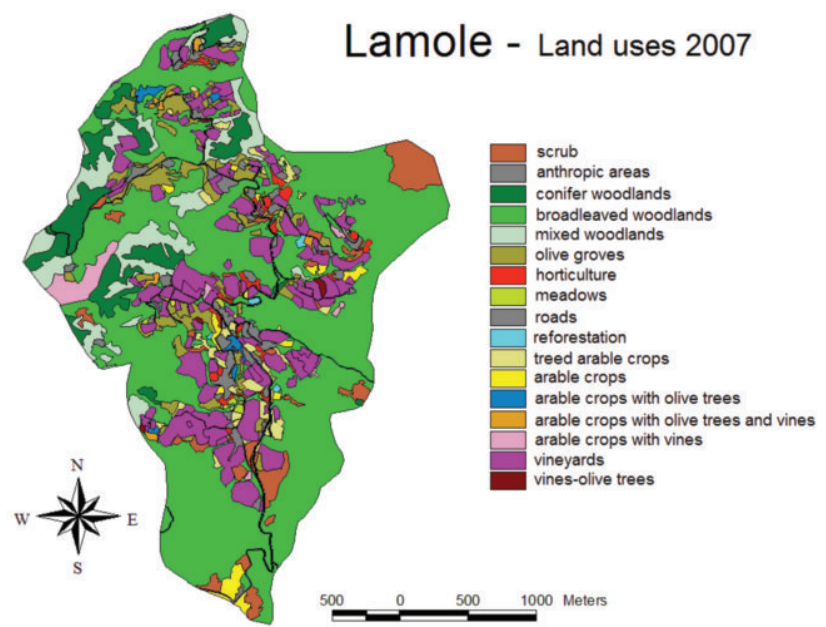

Figure 5. Map of the land uses in 2007 (Lamole study area).

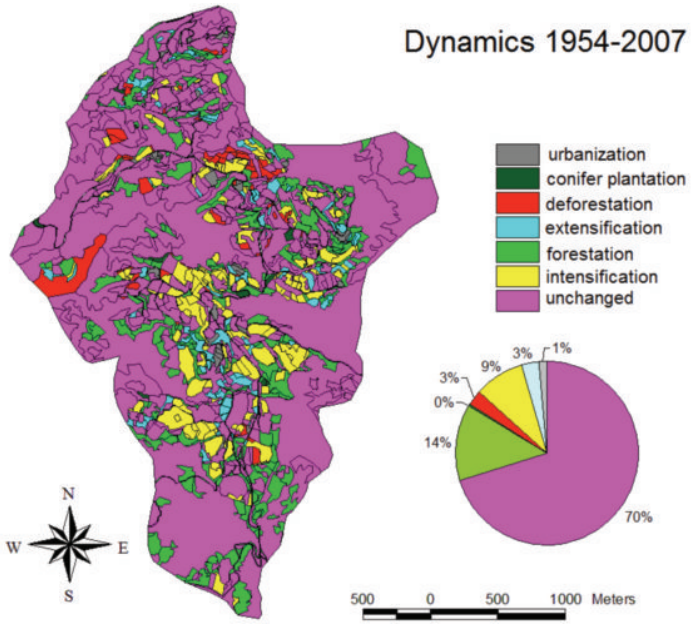

Figure 6. Map and percentages of the principal evolutionary dynamics for the period 1954-2007 (Lamole study area).

Table 3. Land use classification for 2007 (Lamole study area).

\begin{tabular}{lrr} 
Land use 2007 & Area (ha) & $\%$ \\
Anthropic areas & 25.04 & 3.57 \\
Horticulture & 7.43 & 1.06 \\
\hline Broadleaved woodland & 352.43 & 50.29 \\
Conifer woodland & 44.17 & 6.30 \\
\hline Mixed woodland & 50.46 & 7.20 \\
Reforestation & 1.17 & 0.17 \\
\hline Scrub & 31.68 & 4.52 \\
Arable crops & 9.21 & 1.31 \\
\hline Treed arable crops & 13.48 & 1.92 \\
Contour planted vineyard & 34.03 & 4.86 \\
\hline Longitudinal vineyard & 64.99 & 9.27 \\
Olive grove with regular layout & 14.10 & 2.01 \\
\hline Olive grove with irregular layout & 23.36 & 3.33 \\
Vines-olive trees & 1.26 & 0.18 \\
\hline Meadows & 1.48 & 0.21 \\
Arable crops with olive trees & 2.81 & 0.40 \\
\hline Arable crops with vines & 10.04 & 1.43 \\
Arable crops with olive trees and vines & 3.54 & 0.51 \\
\hline Roads & 10.11 & 1.44 \\
Total & 700.81 & 100.00 \\
\hline
\end{tabular}


Cross tabulation allows the changes to the Lamole landscape to be analyzed in detail (Table 4).

The surface increase in wooded areas is mainly through forestation, while conifer plantations involve just 2.6 hectares, and only a small part of the woodland expansion is contrasted by deforestation. Most of the forestation has replaced inter-cropping, olive groves and arable crops, indicating a partial and significant abandoning of farmlands, on an area of around 65 hectares. Part of the deforestation involves scrublands, that pass from 49.7 hectares in 1954 to around 32 in 2007, which are eliminated to make way for new specialized crops, mainly vineyards. The expansion of conifer woodlands is not always due to conifer plantations but in most cases a change in composition of mixed and broadleaved woodlands, passing from 11 hectares in 1954 to 44 hectares in 2007. Although there are new conifer woodlands on land at one time occupied by agricultural areas, most of these new 33 hectares are on ex broadleaved woodlands. Intensification is mostly due to the planting of specialized vineyards in place of other crops, in particular inter-cropping and arable crops, while olive groves have instead undergone a drastic reduction from approximately 111 hectares to just 37 .

The land uses typifying the Lamole landscape after the second World
War come under the heading of inter-cropping, that despite the strong reduction in area $(-55 \%)$, still conserves all the types that were identified for 1954 .

\section{Terracing}

One of the main elements that have characterized the Lamole agricultural landscape, like many hilly and mountainous areas in central Italy, are the terraces, thanks to which it has been possible to cultivate otherwise unsuitable steeply sloping land. In 1954 there were many more terraced areas than today. More specifically, there were 749 stone walls with total length of 51,875 metres, whereas now there are 515 stone walls with a total length of 30,694 metres. Apart from the absolute values, it is interesting to cross tabulate these data with those relative to land uses, to analyze which crops were grown on terracing in the past and which are now. In 1954, $45 \%$ of the terraces were associated with olive-growing, $33 \%$ with inter-cropping, $10 \%$ was used for arable crops, and only $2 \%$ was occupied by vineyards in monoculture. Despite the strong regression in the olive-growing sector, in $200731 \%$ of the terraces continue to be used for olive-growing, and more than half of the olive groves are found on terraced land. Twenty-eight per-

Table 4. Cross tabulation of the evolutionary dynamics for the period 1954-2007 (Lamole study area).

Land uses 2007

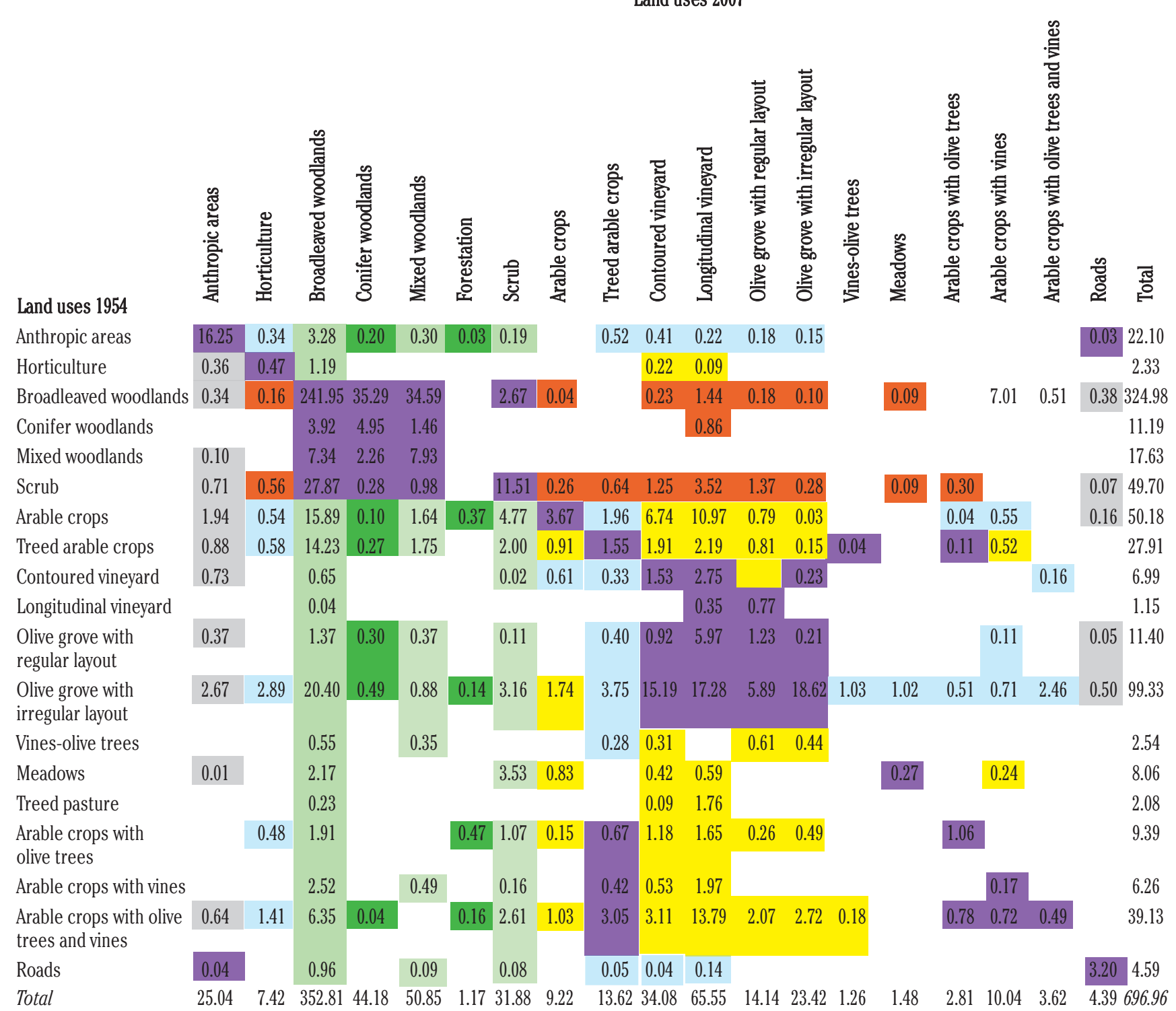


cent of the terraces contain specialized vineyards (but only $17 \%$ of vineyards are found on terraces) and 24\% inter-cropping (Figure 7). These data demonstrate that the Lamole landscape is still today profoundly linked to the presence of terraces, notwithstanding a strong regression. In fact, with less regular maintenance of the dry-stone walls, around $40 \%$ of the terracing has been lost in only fifty years, and $10 \%$ of those still remaining are affected by secondary successions following the abandoning of farming activities. The presence of the terraces currently appears to be more closely linked to the cultivation of olives rather than vines, and the trend towards the reduction in olive groves to make way for vineyards risks leading to the disappearance not only of the olive trees, but also of the terraced landscape.

The density and the intensity of terraces on the two dates are reported in Figures 8 and 9. Despite the class of highest intensity not being present in the Lamole area even in 1954 (a class that is attributed to

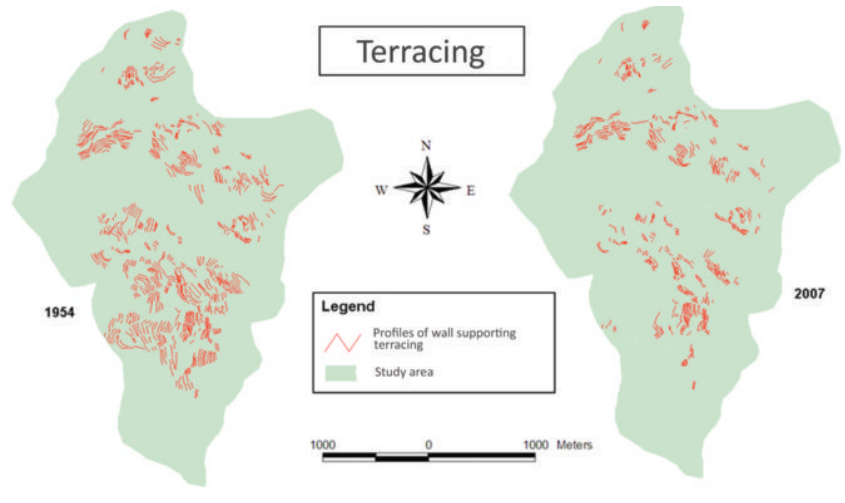

Figure 7. Map of the stone walls supporting terraces in 1954 and 2007 (Lamole study area).
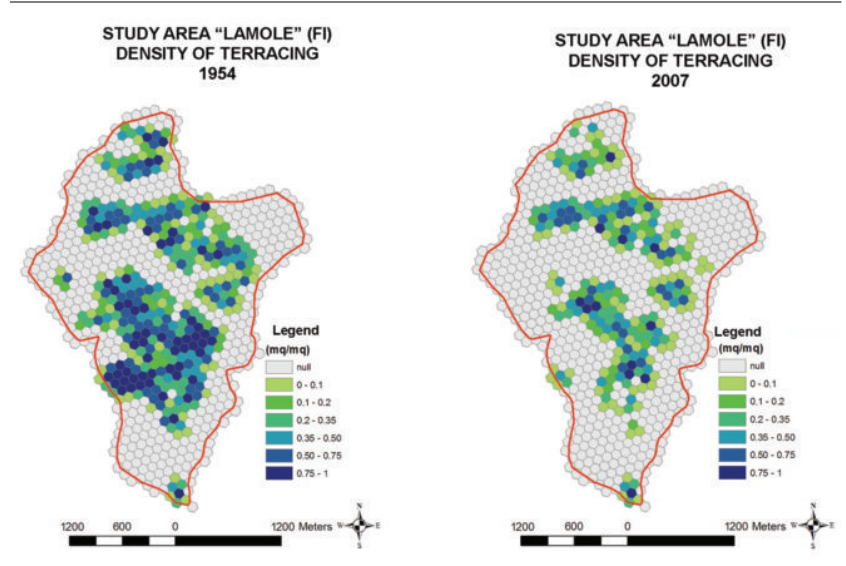

Figure 8. Density of terraces (Lamole study area).
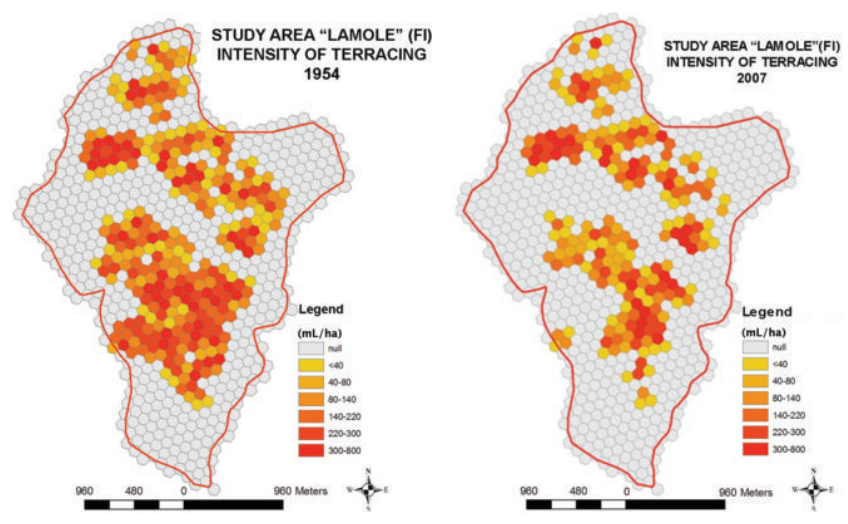

Figure 9. Intensity of terraces (Lamole study area). very unusual situations in the Italian panorama), there is a substantial reduction in the terraces, passing globally from $50 \mathrm{~km}$ to $30 \mathrm{~km}$ of drystone walls, with a reduction of around $40 \%$. The combination of the density and intensity of terracing has led to the classification of the terraced territory showed in Figure 10. The comparison demonstrates the prevalence of landscape types and differences between the two periods measured by the indexes. They are obviously concise classifications that, as is clear from the map, have marked internal variations, but in any case constitute a potentially valuable tool for an initial general characterization, to be able to compare areas that differ by geography, history and land use and assign a more precise geographical nomenclature than those proposed so far (Scaramellini, 2008).

Indexes of landscape ecology

The indexes of landscape ecology (Table 5) demonstrate a tendency towards simplification and homogenization of the landscape mosaic. The fragmentation of the landscape has notably reduced with the passing of time, while the number of land uses has remained constant, indicating that the variety of land uses which characterized the historical landscape has not yet been lost. Sharpe's Index (Figure 11) demon-

Table 5. Indices of landscape ecology.

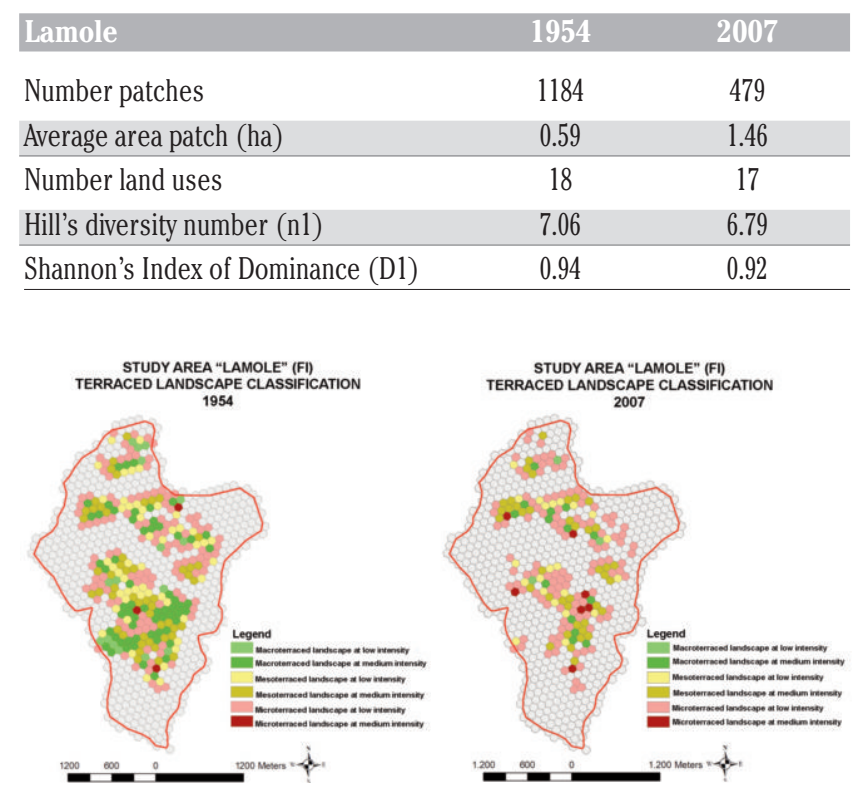

Figure 10. Comparison between classification of the terraced landscape in 1954 and 2007 (Lamole study area).

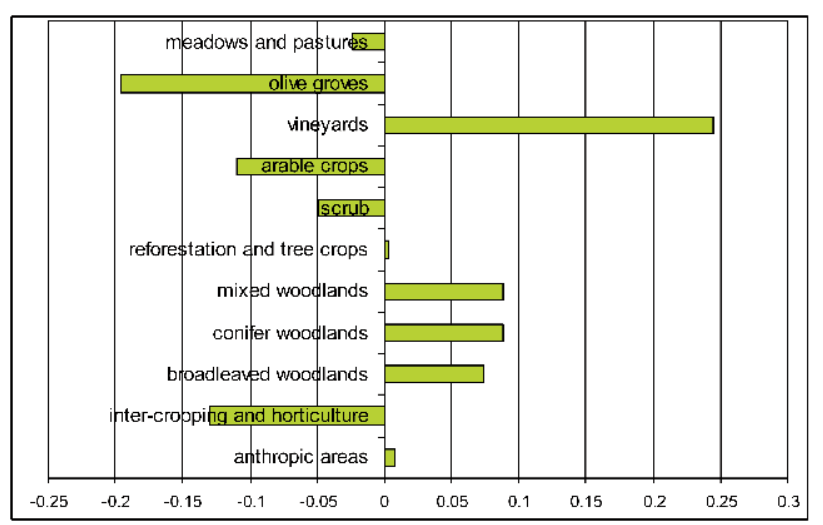

Figure 11. Sharpe's index for the period 1954-2007 (Lamole study area). 
strates that the most significant dynamics are the expansion of specialized vineyards and the consequent reduction in olive groves (from 161 to 45 hectares) and inter-cropping. All types of woodland have increased, whereas scrub areas are in regression due to the expanding of broadleaved woodlands. Arable land also shows a marked diminution caused by the spread of specialized viticulture and phenomena of secondary succession that have led to the expansion of woodland following the abandoning of arable crops.

The Historical Index (Figure 12) makes it possible to highlight the landscape emergencies, i.e. the land uses most at risk of disappearance. The land uses with the highest Historical Index values are meadows and arable crops. Whereas meadows have never been a characteristic element of the local landscape and their disappearance would not endanger maintenance of the historical landscape, for the arable crops, even if they are not one of the principal identifying elements, a strong reduction would certainly lead to an obvious landscape simplification. Olive groves are in strong regression, having been abandoned due to a progressive loss of economic importance, and their maintenance should be one of the main objectives of a correct landscape management, especially of the terraced types $(\mathrm{HI}=4.56)$ with respect to those on flat land $(\mathrm{HI}=2.81)$ and in particular of the terraced olive groves with irregular layout $(\mathrm{HI}=6.3)$, while the non-terraced olive groves with regular layout have a very low value $(\mathrm{HI}=0.2)$, which confirms their recent diffusion.

Inter-cropping is the fourth land use type in order of risk of disappearance, a group of land uses which, due to their structural characteristics, are fundamental for landscape diversification, as historical testimony and reservoir of cultivated biodiversity.

The areas of scrub have also reduced, but their current surface area is still quite high and therefore constitutes an important land use, not only for the landscape role, but also for the habitat they provide, especially for birds. All the other land uses have Historical Index values of less than one, indicating that the current area is larger than that of 1954.

By integrating the Historical Index values with cartographic data, a map (Figure 13) is obtained showing the zones with land uses that are at major risk of disappearance, therefore the most sensitive areas in need of careful conservation. These areas, formed mainly of olive groves, inter-cropping and arable crops, are generally small and located in typically farming areas and along roadsides.

\section{Discussion of the results}

At Lamole, in comparison with other areas of Tuscany, the principal characteristics of the historical landscape have remained in a satisfactory state, notwithstanding many changes to the structure of the landscape mosaic and cropping systems. However, attention should be paid to the vulnerable elements that could compromise the maintenance of traditional systems in the future.

The principal characteristic elements of the historical landscape that should be preserved are the olive groves (especially those with irregular layout and terraced), inter-cropping, arable crops, and the presence of terracing. In reality, the principal element is the complex structure of a highly fragmented mosaic, which must maintain the equilibrium between the various land uses and between the forestry and farming sectors.

The specialized vineyards have progressively expanded since 1954, but some operations of restoration of the historical terracing and their cultivations would seem anyway to exclude any risk of the creation of a landscape of industrial viticulture, as has happened in the majority of the other Tuscan areas producing quality wines (the average vineyard size is still not too large, passing from 0.3 to 0.8 hectares). The restoration of the terraces with contoured layout and their systems for water run-off are due to the realization of the role that traditional practices play in the improvement of the relationship between product quality and landscape quality, and the increased importance given to the role of the landscape by the rural development policies. There has anyway been widespread specialization in viticulture at Lamole, which has contributed towards a homogenization and marked simplification of the structure of the local landscape, with a huge reduction of vines in intercropping and in the contoured layout (in 1954, 86\% of the vineyards were contour planted, today $34 \%$ are, in reality not a too low value). It is therefore necessary to limit the creation of combinations of excessive size and the expansion of vineyards on land used for other crops in order to maintain the variety of cropping systems present in the area. Conservation of the terraces, given the $40 \%$ reduction, must also be a priority for management aimed at maintenance of the historical landscape, by restoring the stone walls in a poor state and protecting no longer cultivated terraces from secondary successions. The loss of the stone walls is in fact not only the loss of an element that strongly characterizes the landscape from the aesthetic point of view, but also the loss of a cultural and historical heritage and of traditional wall-building skills. Lastly, has to be remembered the importance of the terraces and their associated hydraulic systems for water regulation and protection against surface erosion. The results from a research conducted in the Chianti area are emblematic, that following the expansion of cultivations in longitudinal rows, erosion increased by $900 \%$ in the period 1954-76, the annual erosion in the longitudinal vineyards resulted as being particularly intense, at around 230 tha (Zanchi and Zanchi, 2006).

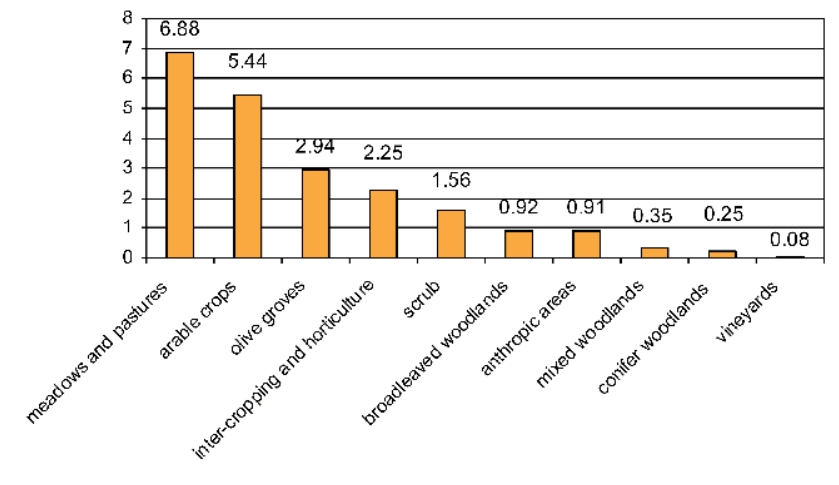

Figure 12. Historical index values for the different land uses (Lamole study area).

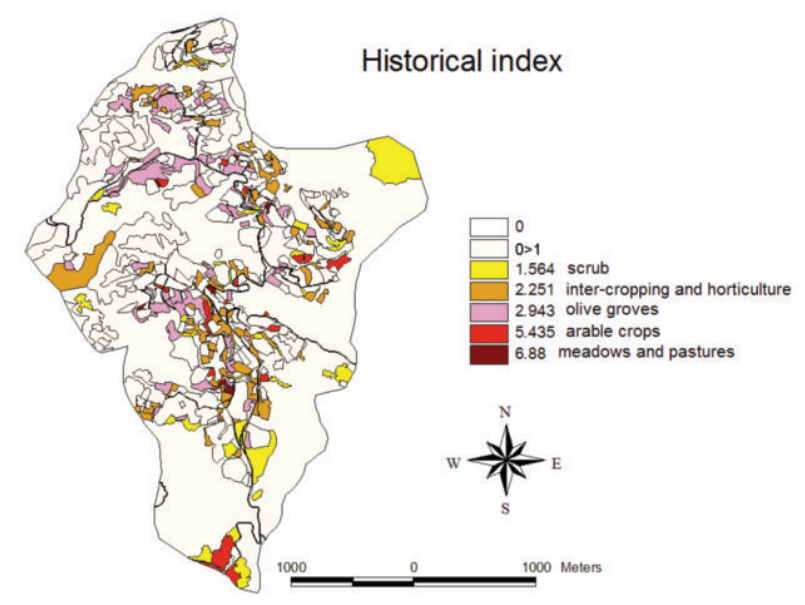

Figure 13. Historical index for the period 1954-2007 (Lamole study area). 
The principal evolutionary dynamics, and one of the main problems throughout the mountain and hill farming areas of the Apennines, is woodland expansion, with the consequent homogenization of the landscape that progressively differs from the traditional one, which was characterized by an equilibrated integration of forested and farmed areas. The management choices aimed at conservation and enhancement of the landscape should therefore be directed towards a correct forestry management, limiting its expansion on new lands and maintaining the open spaces, such as scrublands. Attempts should also be made to promote the recovery of part of the inter-cropping and olive groves with irregular layout, as has been successfully done for the restoration of some historical vine-growing terraces, with the principal menace to the integrity of the remaining historical landscape being the intensification of the viticulture sector and the abandoning of other farming activities.

\section{Costaviola study area - Reggio Calabria}

The study area is situated on the Tyrrhenian coast of Calabria, in the municipalities of Palmi, Seminara and Bagnara Calabra, in the Province of Reggio Calabria. The area is almost totally comprised within the Costa Viola zone and affected by the Costa Viola and Monte S. Elia zones. The lands are mainly privately-owned, lying between 0 and $500 \mathrm{~m}$ a.s.l. The area, covering 764.73 hectares, lies on a geological substrate prevalently formed by amphibolic schists and mica-schists with veins of pegmatite and jalomicte, while the more internal areas have a substrate composed of red clay sands and conglomerates of sandy-clay bound crystalline pebbles.

\section{The landscape in 1954}

The landscape in 1954 is fairly heterogeneous, with a prevalence of farming areas (Figure 14), composed of arable crops (29\% of the study area), vineyards (20\%), inter-cropping (7\%), orchards and horticulture (2\%), and olive groves (1\%), while woodlands cover $31 \%$ of the surface area. The other land use classes identified are: uncultivated grasslands (3\%), barren areas (3\%), meadows (2\%) and anthropic areas (2\%).

Table 6. Land use classification for 1954 in the Costaviola study area.

\begin{tabular}{lcc} 
Land use 1954 & Area (ha) & $\%$ \\
Anthropic areas & 11.06 & 1.45 \\
Vineyards & 152.72 & 19.97 \\
\hline Orchards & 12.23 & 1.60 \\
Meadows & 15.55 & 2.03 \\
\hline Horticulture & 0.64 & 0.08 \\
Broadleaved woodlands & 137.91 & 18.03 \\
\hline Conifer woodlands & 7.57 & 0.99 \\
Scrub & 49.65 & 6.49 \\
\hline Area with scattered vegetation & 42.78 & 5.59 \\
Arable crops & 224.15 & 29.31 \\
\hline Olive groves with regular layout & 6.57 & 0.86 \\
Vines-olive trees & 0.31 & 0.04 \\
\hline Arable crops with olive trees & 21.08 & 2.76 \\
Arable crops with vines & 3.75 & 0.49 \\
\hline Arable crops with olive trees and vines & 25.97 & 3.40 \\
Uncultivated grassland & 24.66 & 3.22 \\
\hline Waters & 3.14 & 0.41 \\
Rocky outcrops & 17.96 & 2.35 \\
\hline Roads & 7.01 & 0.92 \\
Total & 764.73 & 100.00 \\
\hline
\end{tabular}

The agricultural sector has a preponderance of arable crops (50\% of the farmed areas), followed by vineyards (34\%) and inter-cropping (11\%), composed of four different types (Table 6). Olive trees, apart from 6 hectares, are always inter-cropped with vines and arable crops. Indeed, if the different types of inter-cropping are also considered, the percentage of land occupied by olive trees, vines and arable crops in the study area reaches 7, 24 and $36 \%$, respectively. There are also some orchards and some horticulture.

Broadleaved woodlands account for $58 \%$ of woodland, but there are also areas of scattered vegetation and scrub, on 5.6 and $6.5 \%$ of the study area respectively (i.e. 18 and $21 \%$ of the wooded areas), and 7.6 hectares of conifer woodlands ( $3 \%$ of the woodland).

The distribution of land uses in the study area follows its morphology (Figure 15), with two distinct bands: one directly facing the sea, characterized by steep slopes and alternating woodlands and vineyards, the latter growing on the traditional small terraces that typify the local landscape; while the flat internal area, at around $400-500 \mathrm{~m}$ a.s.l., is mainly used for arable crops, with large fields (up to 30 hectares), and a highly fragmented mosaic of inter-cropping in the southern part.

\section{Today's landscape}

The Costa Viola landscape in 2007 appears to be dominated by woodland and scrub, which now cover $44 \%$ of the surface (Figure 16). The characteristic land uses, arable crops and vineyards, are instead in net reduction, and are found on $17 \%$ and $12 \%$, respectively. These are followed by uncultivated grassland (13\%), olive groves (4\%), anthropic areas (4\%), inter-cropping (3\%), barren areas (2\%), orchards and hor-

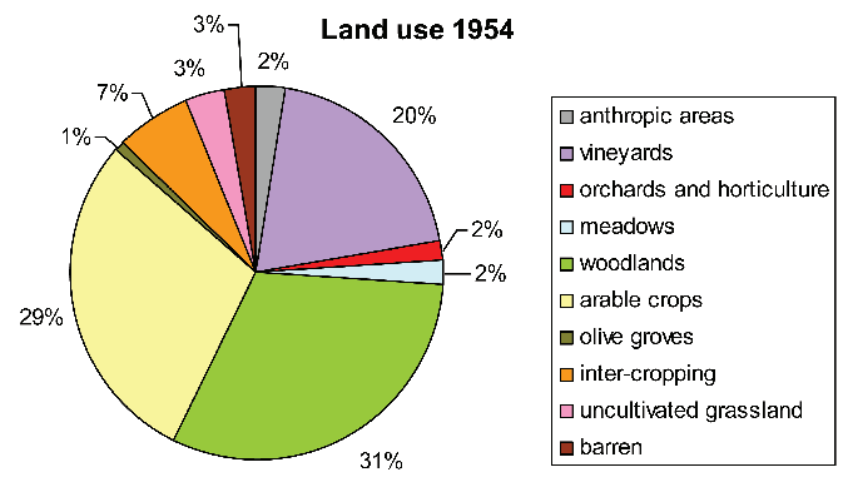

Figure 14. Percentages of land use cover for 1954 (Costaviola study area).

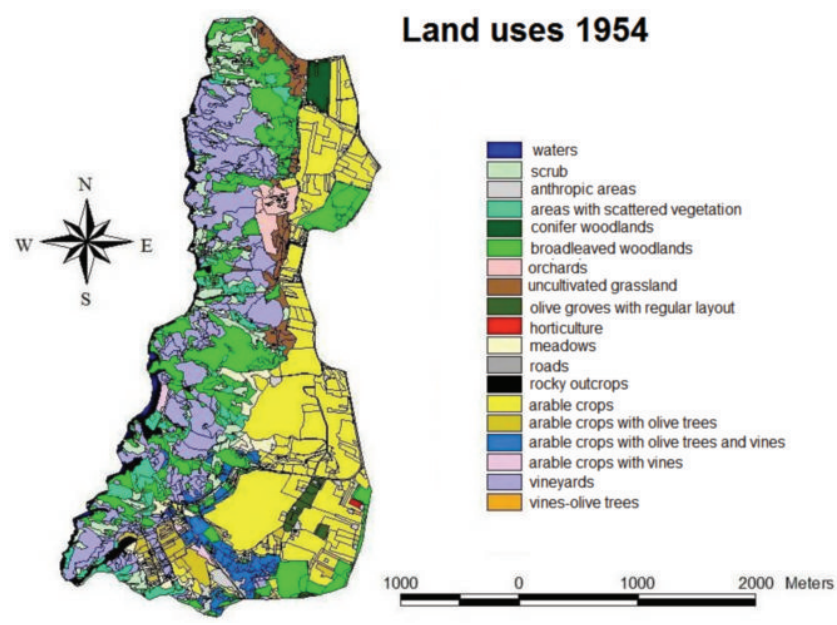

Figure 15. Map of the land uses in 1954 (Costaviola study area). 
ticulture (1\%). Of the wooded areas and scrub, the most widespread are broadleaved woodlands ( $51 \%$ of the category), but the notable amounts of scrub (35.5\%) and areas with scattered vegetation (6\%) indicate the widespread presence of secondary successions on land at one time used for farming.

Altogether, the lands used for agriculture are $37 \%$ of the entire study area, and the most widespread are arable crops (47\% of the cultivated areas), mainly located in the flatter inland area (Figure 17) followed by vineyards (32\%), which still represent the characteristic element of the area, and olive groves (12\%), which are found mainly in the southern part of the area with both regular layout, the majority, and scattered. Of great importance is the maintenance of small plots used for inter-cropping (7\% of the cultivated areas) with arable crops, olive trees and vines (Table 7). Uncultivated grasslands are now found over $13 \%$ of the area, a sign of widespread crop abandoning, while orchards have disappeared and horticulture survives only in the south of the study area.

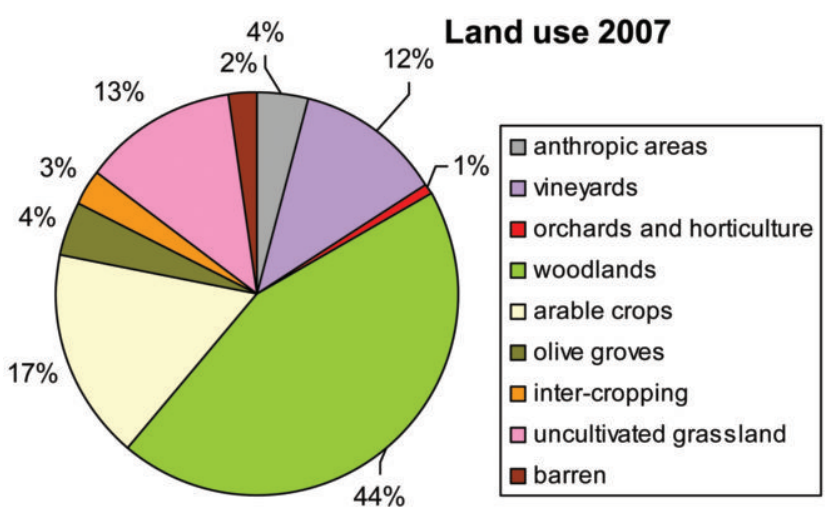

Figure 16. Land use cover percentages for 2007 (Costaviola study area).

Table 7. Land use classification for 2007 in the Costaviola study area.

\begin{tabular}{lcc} 
Land use 2007 & Area (ha) & $\%$ \\
Anthropic areas & 22.82 & 2.98 \\
Vineyards & 90.54 & 11.84 \\
\hline Horticulture & 4.65 & 0.61 \\
Broadleaved woodlands & 174.99 & 22.88 \\
\hline Conifer woodlands & 17.09 & 2.23 \\
Mixed woodlands & 5.75 & 0.75 \\
\hline Scrub & 120.97 & 15.82 \\
Area with scattered vegetation & 21.64 & 2.83 \\
\hline Arable crops & 131.11 & 17.14 \\
Treed arable crops & 0.51 & 0.07 \\
\hline Olive groves with regular layout & 26.60 & 3.48 \\
Olive groves with irregular layout & 6.02 & 0.79 \\
\hline Arable crops with olive trees & 10.59 & 1.38 \\
Arable crops with vines & 3.94 & 0.51 \\
\hline Arable crops with olive trees and vines & 5.69 & 0.74 \\
Uncultivated grassland & 97.08 & 12.70 \\
\hline Waters & 3.14 & 0.41 \\
Rocky outcrops & 13.21 & 1.73 \\
\hline Roads & 8.41 & 1.10 \\
Total & 764.73 & 100.00 \\
\hline & & \\
\hline
\end{tabular}

Landscape changes in the period 1954-2007

During the last fifty years the Costa Viola landscape has undergone many changes, most of which have involved the traditional elements that ensured characteristics of uniqueness to the local landscape; despite this, $63 \%$ of the area remains unaltered (Figure 18). The main process identified by the analysis of the evolutionary dynamics is the increase in woodlands, in particular forestation (on 15\% of the area), while the colonization of farmland by conifer woods is limited (1\%). The second dynamic process in order of importance is extensification (13\%), followed by intensification (3\%), deforestation (3\%) and urbanization (2\%).

The two principal dynamics identified, the increase in woodlands and extensification, which together cover $28 \%$ of the study area, are closely connected to the abandoning of farming activities and phenomena of secondary succession. As can be noted from the cross tabulation (Table 8), $52 \%$ of forestation happens on ex-vineyards, abandoned because of the difficult working conditions and low earnings from viticulture. This process is mostly localized in the areas with steeper slopes, on the terraces traditionally used for vines, but difficult to

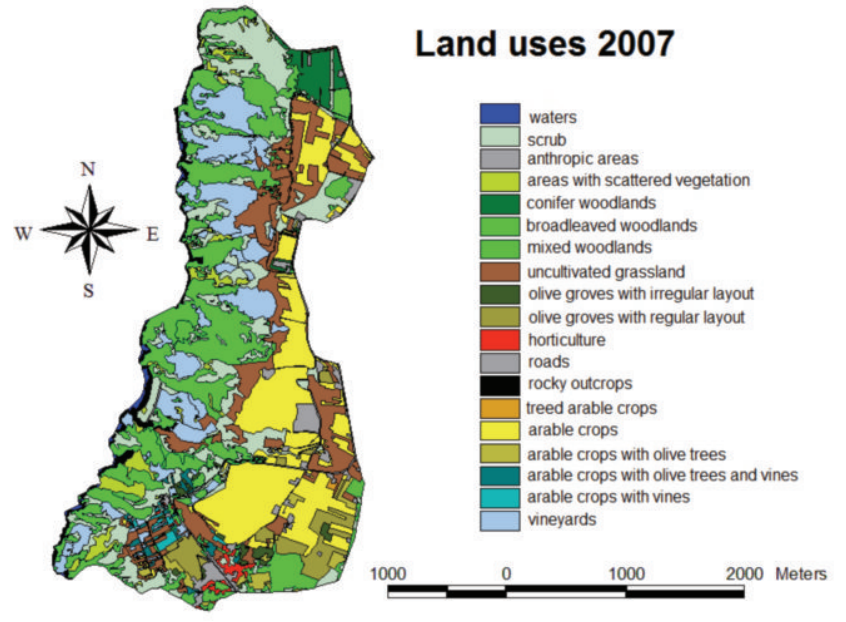

Figure 17. Map of the land uses in 2007 (Costaviola study area).

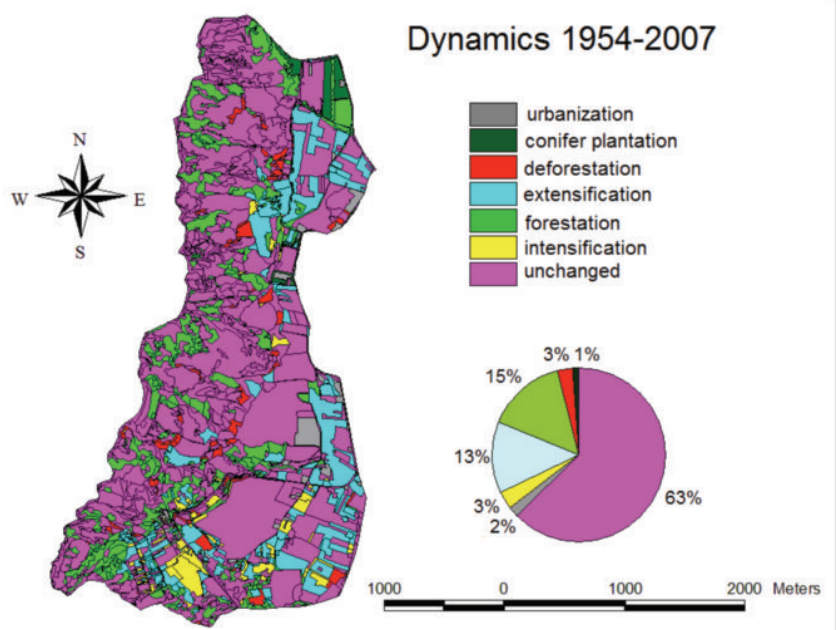

Figure 18. Map and percentages of the principal evolutionary dynamics for the period 1954-2007 (Costaviola study area). 
mechanize. Moreover, about $54 \%$ of the forestation is in the form of scrub and areas classified as scattered vegetation, a sign that the abandoning of the crops is quite recent. Conifers are limited to the extreme north of the study area, in correspondence to a probable reforestation operation.

Extensification also mostly involves vineyards, but is also found on lands at one time used for arable crops, which, like the vineyards, have undergone a decided contraction in the period 1954-2007 (-41\%). About $43 \%$ of the old farmlands involved in extensification are today classifiable as uncultivated, which means that in the not too distant future they will also probably be invaded by scrub vegetation, followed by trees. Intensification, even if a minor process, $73 \%$ of which is occurring on inter-cropping, is concentrated mainly in the south of the study area, i.e. with gentler slopes and better served by roads, where farming costs are lower. Vineyards, the characteristic element of the area, are still present, even if greatly reduced (-41\%), as is inter-cropping (-60\%), and their conservation should be a priority.

\section{Terracing}

The Costa Viola has a high steeply sloping coastline, but with a particularly suitable microclimate for vine-growing. For centuries man has remodelled the land to render it cultivable, building hundreds of kilometres of dry-stone walls to support small terraces no more than 3-4 metres wide, almost all growing pergola-trained vines. However, the very steep slopes limit the use of machinery, so cultivation of these small and almost inaccessible terraces has become increasingly onerous and less remunerative, and the terraces have been progressively abandoned and invaded by scrub and tree vegetation, even if the majority of the walls are still in a good state of repair (Figure 19).

In 1954 some terraces had already been invaded by vegetation (20\%), but most of the coast still had a terraced landscape characterized by intense farming activity. Instead, almost $40 \%$ of the terraces show signs of abandonment and secondary successions in 2007 (Figure 20 ). The maintenance and restoration of the stone walls and terraced cultivations therefore appears even more necessary. Leaving aside their landscape and historical-cultural significance, they play a funda-

Table 8. Cross tabulation of the evolutionary dynamics for the period 1954-2007 (Costaviola study area).

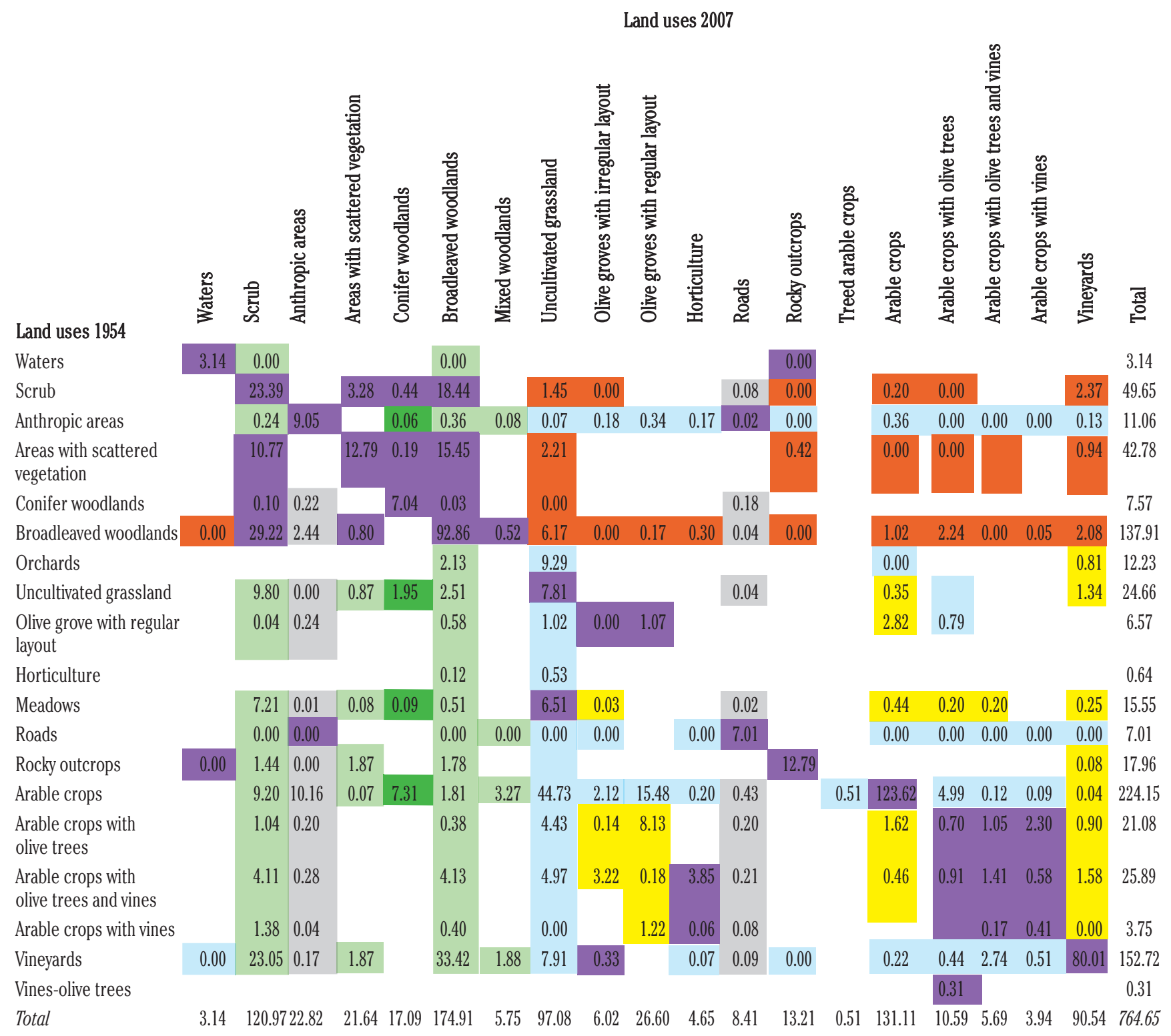


mental role in impeding phenomena of erosion and landslides that occur on such steep slopes, which are already evident in the few areas where the stone walls are in ruins, where landslides, sometimes big ones, are frequent.

The density of the terracing (Figure 21) is very high, with a significant presence of the highest class (microterraced landscape), demonstrating the almost uniform structure of the terraced system. This indicator is only reported for 2007, as the variations since 1954 have not regarded so much the loss of terraces, but rather their abandoning.

The terracing intensity (Figure 22) appears to be prevalently of the highest class, demonstrating an extremely well-developed terracing. The classification of the terracing (Figure 23) demonstrates a conspicuous presence of a landscape macroterraced at high intensity and shows the capacity of the classification method used to separate this situation from the one previously analyzed at Lamole.

\section{Indexes of landscape ecology}

Analysis of the historical landscape demonstrates the presence of a mosaic traditionally dominated by few land uses and by medium-large sized patches, except for a small area where a highly fragmented mosaic is found. The values of the indexes (Table 9) should be read as a loss of the traditional landscape systems (further increase in the average area of the patches, diminution of Shannon's Index of Dominance), in a phase of evolution characterized by the abandoning of vineyards and the consequent increase in scrub and tree vegetation.



Figure 19. The terracing of Costaviola.

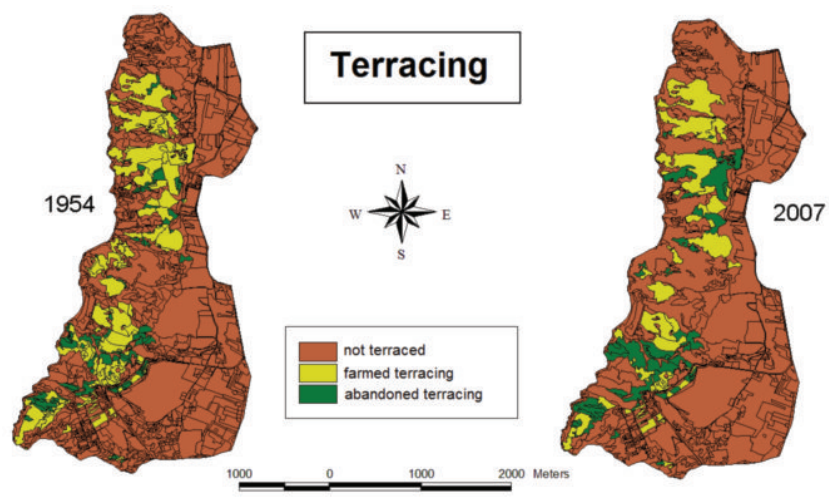

Figure 20. Location and conservation state of the terraces. Comparison between 1954 and 2007 (Costaviola study area).
Table 9. Indexes of landscape ecology.

\begin{tabular}{lcc} 
Costaviola & 1954 & 2007 \\
Number of patches & 1358 & 602 \\
Average area patch (ha) & 0.56 & 1.27 \\
\hline Number land uses & 19 & 19 \\
Shannon's Index of Dominance & 0.81 & 0.71 \\
\hline Hill's diversity number & 8.46 & 9.29 \\
\hline
\end{tabular}

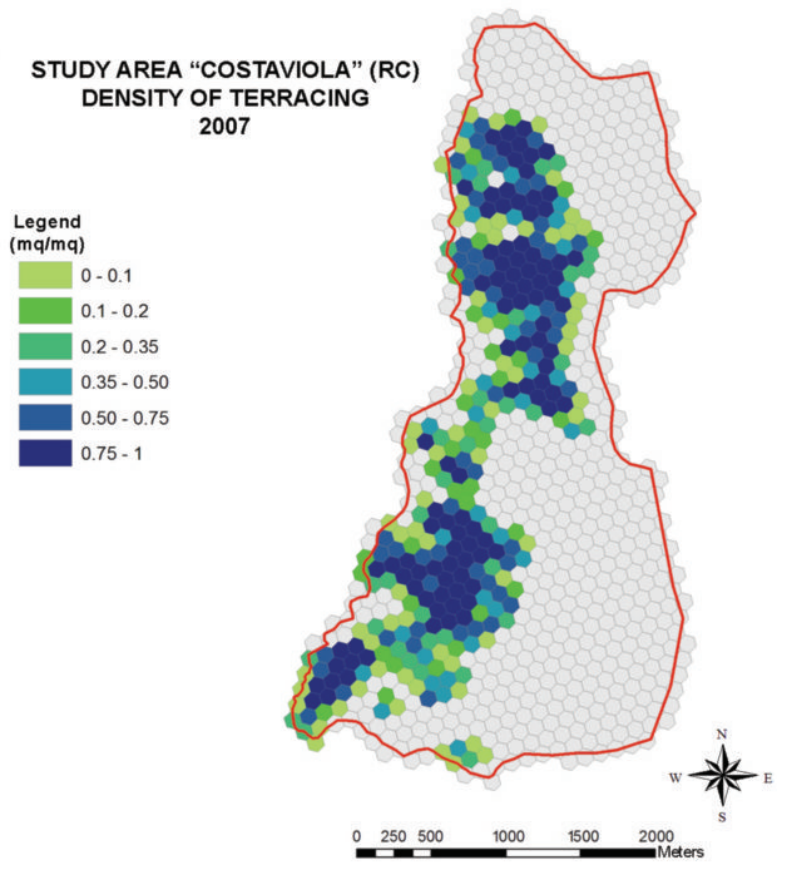

Figure 21. Density of terracing (Costaviola study area).

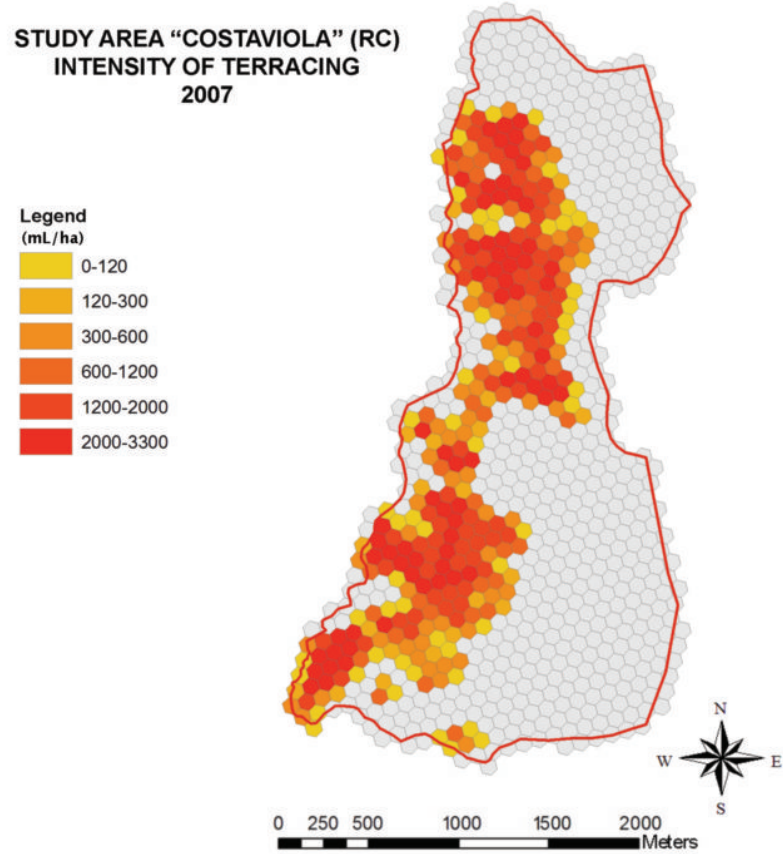

Figure 22. Intensity of terracing (Costaviola study area). 
Sharpe's Index (Figure 24) confirms the previous data, and shows that the most important regressive processes are those related to the land uses of historical importance (vineyards, arable crops and intercropping). Their reduction is mainly balanced by the expansion of wasteland, scrub and wooded areas, formations indicative of processes of abandoning and secondary successions.

The value for olives refers only to olive groves in monoculture, which have increased since 1954, but overall the total olive-growing area has not changed very much (7\% of the study area in 1954 and $6.4 \%$ in 2007) as the inter-cropping of olive trees, arable crops and vines was common in 1954. The land uses with the highest Historical Index values (Figure 25) are horticulture, orchards and inter-cropping, cropping types linked to traditional farming activities, which although limited in terms of total area, add notable quality to the landscape mosaic of the Costa Viola. These are followed by areas with scattered vegetation, a land use linked to phenomena of abandoning, which should therefore not be a priority as regards conservation of the historical landscape as it is reduced by the arrival of secondary successions.

Arable crops and vineyards are instead the two identifying land uses of the farming landscape, and therefore necessitate careful management as any further reduction would signify an important loss of overall quality of the local landscape. Vineyards in particular register a strong contraction (-41\%), even if the viticulture landscape still retains significant aspects, with a good total expanse of vine-growing terraces, and maintenance of the different types of inter-cropping of vines, arable crops and olive trees, typical land uses of high historical and landscape importance. All the other land uses have values of between 0 and 1 , which is a sign of their expansion over the territory between 1954 and 2007. These include olive groves, but in reality it is only the olive groves in monoculture that are spreading.

The terraces have been progressively abandoned, and this trend is also demonstrated by the Historical Index. The Index value calculated for the terraced land still utilized for farming is 1.42 , demonstrating that maintenance of these terraces must constitute a priority for the conservation of the local historical landscape and also as a defence against the risk of landslides and surface erosion.

The Historical Index map (Figure 26) shows that there are essential-

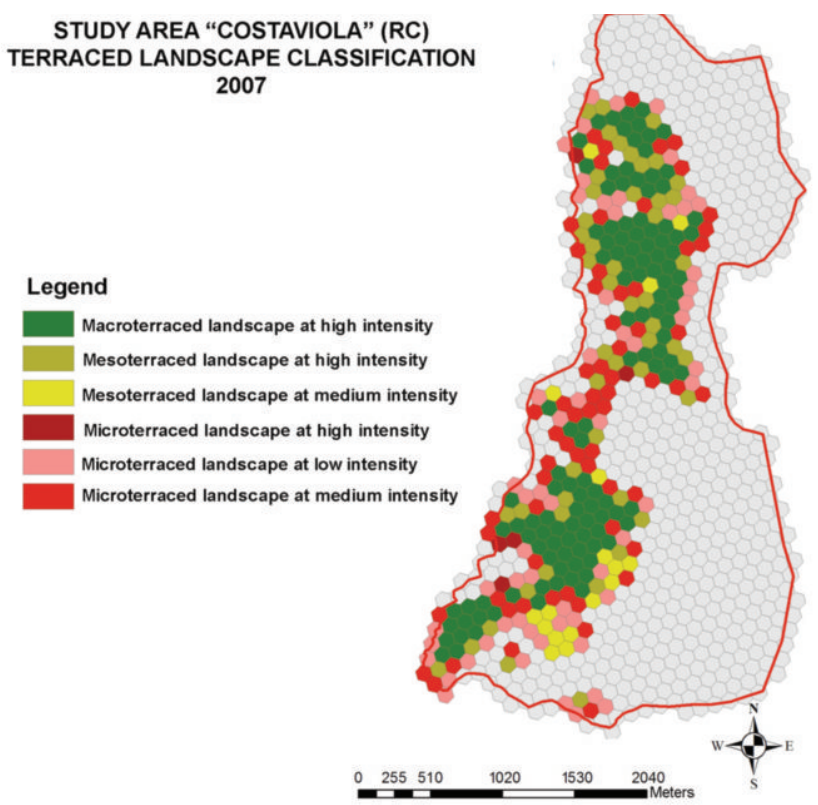

Figure 23. Classification of the terraced landscape (Costaviola study area).

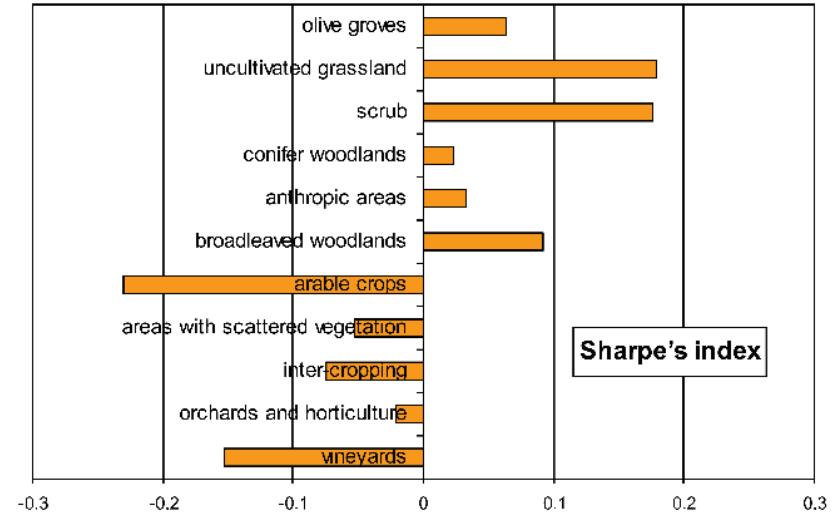

Figure 24. Sharpe's Index for the period 1954-2007 (Costaviola study area).

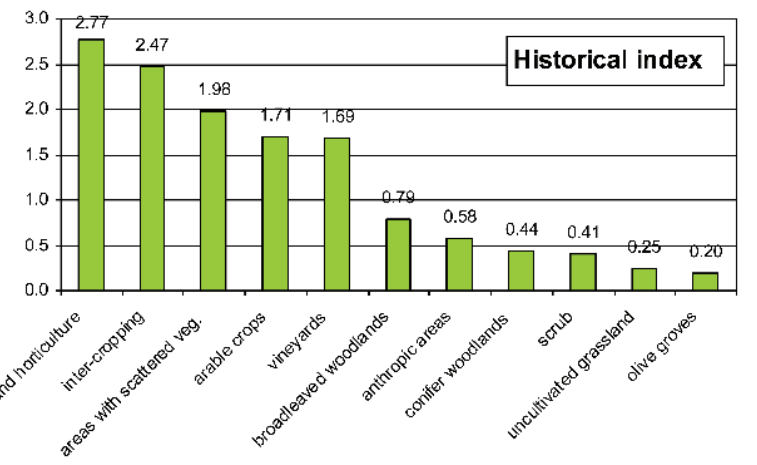

Figure 25. Historical Index values for the various land uses (Costaviola study area).

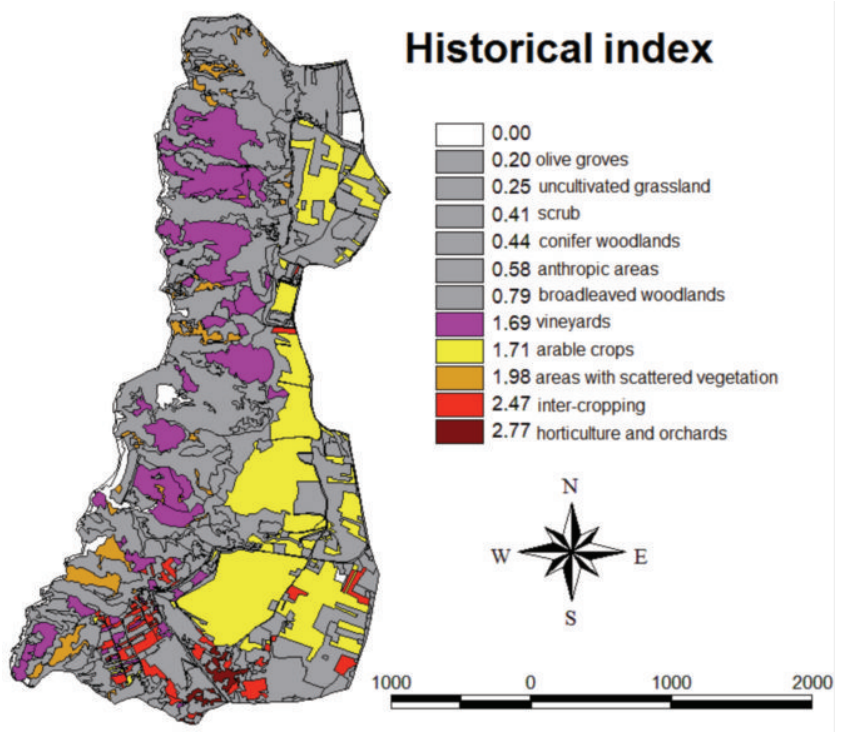

Figure 26. Historical index for the period 1954-2007 (Costaviola study area). 
ly three zones with major landscape emergencies. One is the coastal area with terraced vineyards, while another is the one inland from the coast where arable crops are found. But the zone where the land uses at greatest risk of disappearance are concentrated is, without doubt, the southern part of the study area, around Ceramida (in the municipality of Bagnara Calabra), in which a highly fragmented mosaic still exists, with horticulture, inter-cropping and vineyards. The areas with scattered vegetation should not be considered a characteristic land use at risk of disappearance, but rather as the first sign of the abandoning of farming activities.

\section{Discussion of the results}

The Costa Viola landscape stills retains part of the characteristic elements of the historical systems with an integrity that is still generally good, with steep sea cliffs intricately terraced and cultivated with vines, the hinterland with widespread arable crops, and the south with a complex mosaic of small areas cultivated with horticultural produce and inter-cropping.

Even if all these elements still persist, the multi-temporal analysis and calculation of Sharpe's Index and the Historical Index have demonstrated the true magnitude of the abandoning of farming activities, the principal cause of vulnerability of the local historical landscape, which is more critical among the traditional land uses (arable crops, vineyards and inter-cropping). In particular, in the absence of a stable market that guarantees a suitable distribution network for the local wines and satisfactory income for the producers, the gradual abandoning of the vineyards is inevitable, because they are grown almost exclusively on small terraces on steep slopes, and are therefore labour-intensive and difficult to mechanize.

In order to preserve the historical landscape of Costa Viola it is therefore necessary to develop projects and policies in support of the traditional farming activities, in particular viticulture, the conservation of which, being linked to the maintenance of the terraces, has an importance that goes well beyond just the conservation of an aesthetic and cultural heritage. Indeed, the terraces are a defence against surface erosion and landslides, phenomena that can also be dangerous for humans, given that there are beaches and a stretch of the coastal railway line that runs past the foot of the steep cliff. Where the vineyards are being abandoned and stone walls less maintained, landslides are frequent and are now one of the main problems of the entire Costa Viola, also outside the study area (Nicolosi and Caramberi, 2007).

The case of Costa Viola is therefore emblematic of the close correlation of the abandoning of farming activities, the need for markets that support the typical local products and conservation of the traditional landscape with the need to protect the territory against landslides and erosion.

\section{Valdobbiadene study area - Treviso}

The study area is in the territories of the municipalities of Farra di Soligo and Valdobbiadene, in the Province of Treviso, and extends for around 1152 hectares. It is an area of very closely spaced ridges lying in an east-west direction at the northern limit of the Treviso plain, with an elevation of between 130 and 350 metres a.s.l.

The geological substrate is composed of polygenic conglomerates with thick beds of pebbles alternating with narrow marl-clay lentils in the hills furthest south; moving northwards the hills are of marl clays, sandy clays or sands with stony layers, while the most northerly ridges are formed by molasses, marls and grey-green marl clays.

For technical reasons the first date chosen for the multi-temporal comparison is 1960, as the detail in the 1954 aerial photos was insufficient because of a high flight altitude.

\section{The landscape in 1960}

The landscape of the Valdobbiadene hills in 1960 (Figure 27) is dom- inated by two types of land use, vineyards and woodlands, which cover $43 \%$ and $38 \%$ of the study area respectively. These are followed by meadows and pastures, inter-cropped areas and anthropic areas, each one on $6 \%$ of the surface area. Arable crops are instead only found on $1 \%$ of the area, so are not a characteristic land use. The main type of vineyard are those planted following the contours (Table 10), which represent $97 \%$ of this land use, and are traditionally grown on earth terraces on very steeply sloping land, which would otherwise be impossible to cultivate. The few vineyards with longitudinal rows are mainly concentrated in the flatter part of the study area. The most widespread type of woodland is that of broadleaved woodlands ( $97 \%$ of the wooded areas), whereas scrub and mixed woodlands are sporadic. The meadow and pasture areas are important, both open and treed, which form a belt that runs in a south-west north-east direction in the part of the study area at higher altitude, where the livestock were probably taken to graze in the summer.

Among the farming areas, apart from vineyards, the most common land use is that of arable crops with vines, a traditional type of intercropping practised in the valley bottoms and on the plain, followed by treed arable crops and orchards. Arable crops are only found in small areas on the plain.

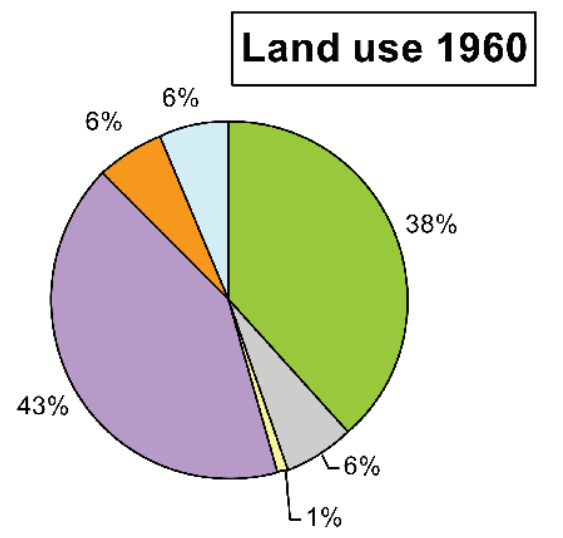

\begin{tabular}{|l|}
$\square$ woodland areas \\
$\square$ anthropic areas \\
$\square$ arable crops \\
$\square$ vineyards \\
$\square$ inter-cropping \\
$\square$ meadows and \\
pastures
\end{tabular}

Figure 27. Percentages of land use cover for 1960 (Valdobbiadene study area).

Table 10. Land use classification for 1960 (Valdobbiadene study area).

\begin{tabular}{lrr}
\hline Land use 1960 & Area (ha) & $\%$ \\
Scrub & 11.58 & 1.00 \\
Anthropic areas & 52.17 & 4.53 \\
\hline Broadleaved woodlands & 426.83 & 37.05 \\
Mixed woodlands & 2.45 & 0.21 \\
\hline Orchards & 13.07 & 1.13 \\
Pasture & 1.10 & 0.10 \\
\hline Treed pasture & 48.97 & 4.25 \\
Meadows & 19.84 & 1.72 \\
\hline Meadow treed & 3.75 & 0.33 \\
Roads & 22.14 & 1.92 \\
\hline Treed arable crops & 16.71 & 1.45 \\
Arable crops & 10.38 & 0.90 \\
\hline Arable crops with vines & 41.40 & 3.59 \\
Contoured vineyards & 467.85 & 40.61 \\
\hline Longitudinal vineyards & 13.78 & 1.20 \\
Total & 1152.04 & 100.00 \\
\hline
\end{tabular}


The layout of the land uses in 1960 (Figure 28) is closely correlated to the morphology of the territory; the pastures and meadows and some woodland formations are at the highest altitudes, while the anthropic areas and different types of farmland are to be found in the flatter zone. The intermediate band, characterized by low but steep hills, is divided between traditional contour-planted vineyards on the south-facing slopes, and small woodlands on the north-facing slopes and in the small valleys between the hills.

\section{Today's landscape}

The landscape in 2007 continues to be dominated by vineyards and woodlands, but the ratios have changed, and other land uses have markedly increased to the detriment of some traditional crops (Figure 29). Wooded areas have become the most common land use classes (48\% of the surface area), while vineyards cover $38 \%$. Among the other land uses the only type with a significant expanse are anthropic areas (12\%), while meadows and pastures, arable crops and inter-cropping together total only $2 \%$ of the study area. Broadleaved woodlands are still the most widespread type of wooded area, covering $46.5 \%$ of the study area ( $97.7 \%$ of the forest areas), followed by scrub and mixed woodlands (Table 11).

Traditional contour-planted vineyards are still the most widespread type (93\% of the vineyards), but there is a tendency towards an increase of the layouts in longitudinal rows and a regression of those contoured with respect to 1960 .

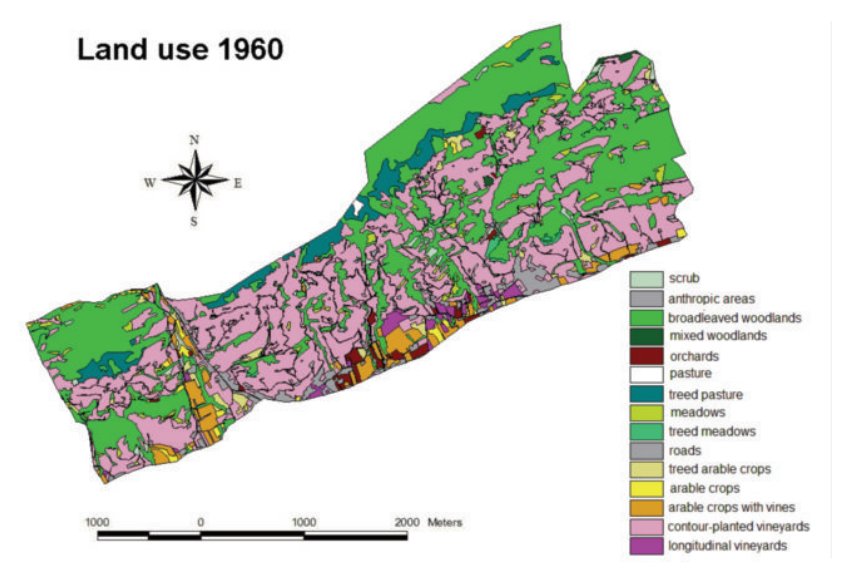

Figure 28. Map of the land uses in 1960 (Valdobbiadene study area).

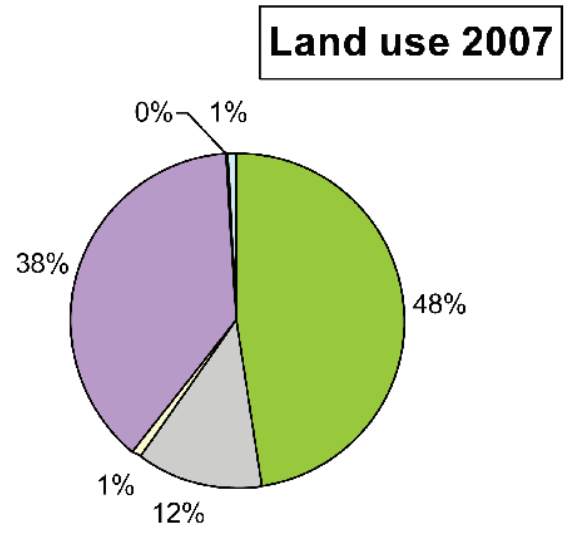

The arable crops remain almost unaltered, with only a slight reduction, while open areas (meadows and pastures) and inter-cropping have practically disappeared, with obvious negative effects on the landscape quality, in that they were the land uses that characterized the zones at higher and lower altitudes, respectively. The map of land uses in 2007 (Figure 30) shows that there has been a simplification of the landscape at the highest and lowest altitudes. In the former, woodlands have colonized the abandoned pastures and meadows, while on the plain the advance of urban areas united with the planting of new specialized vineyards, has eliminated almost all the inter-cropping from the landscape mosaic. The central belt is still dominated by contourplanted vineyards and by wooded areas, which have anyway spread.

\section{Landscape changes in the period 1960-2007}

The principal characteristics of the traditional Valdobbiadene landscape have remained almost intact over the last fifty years, even if there have been changes to land use and the structure of the landscape mosaic. Although there are no significant changes on $75 \%$ of the study area, there are important dynamics (Figure 31), like forestation on $12 \%$ of the area, followed by urbanization (on $6 \%$ ), intensification (4\%), deforestation (2\%) and extensification (1\%).

Forestation is a process that for $44 \%$ affects open spaces, like meadows and pastures, treed and not, land uses that were to be found at the highest altitudes, which no longer being used for grazing, have been gradually colonized by woodland through secondary successions, with

Table 11. Land use classification for 2007 (Valdobbiadene study area).

\begin{tabular}{lrc} 
Land use 2007 & Area (ha) & $\%$ \\
Scrub & 8.99 & 0.78 \\
Anthropic areas & 115.61 & 10.04 \\
\hline Broadleaved woodlands & 535.72 & 46.50 \\
Mixed woodlands & 3.68 & 0.32 \\
\hline Horticulture & 0.30 & 0.03 \\
Meadows & 8.94 & 0.78 \\
\hline Roads & 25.02 & 2.17 \\
Arable crops & 7.11 & 0.62 \\
\hline Arable crops with vines & 3.66 & 0.32 \\
Contoured vineyard & 413.06 & 35.85 \\
\hline Longitudinal vineyard & 29.94 & 2.60 \\
Total & 1152.04 & 100.00 \\
\hline
\end{tabular}

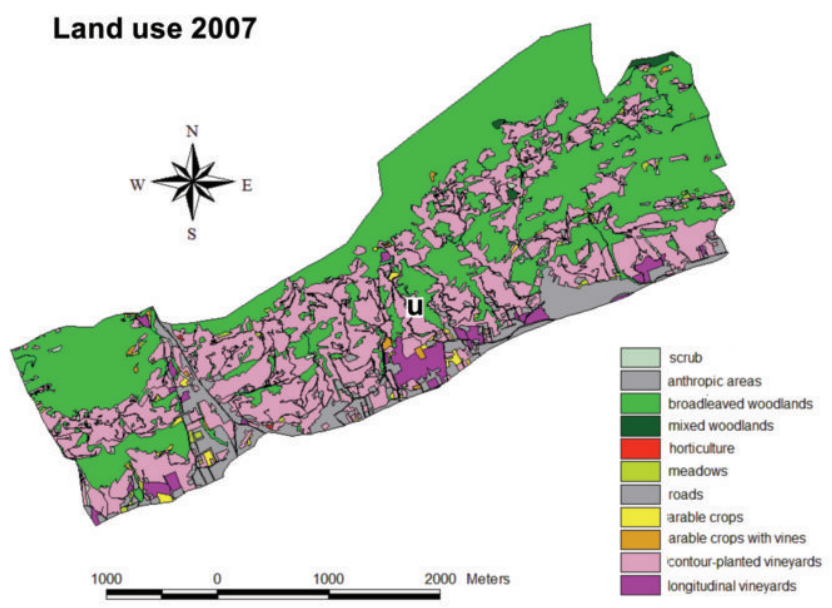

Figure 30. Map of the land uses in 2007 (Valdobbiadene study area).

Figure 29. Percentages of land use cover for 2007 (Valdobbiadene study area). 
the consequent disappearance of a characteristic element of great landscape and ecological importance (Table 12). 49.8\% of forestation has involved lands that were occupied by contour-planted vineyards in 1960, the sign of a not negligible abandoning of traditional vineyards, probably those further from the roads and less remunerative.

The second dynamic in order of importance is the expansion of builtup areas on the plain, much of which is on land at one time used for inter-cropping, especially arable crops with vines, a typical land use in the area at the foot of the hills, which is now reduced to just over 3 hectares, whereas there were more than 40 in 1960. The arable crops with vines have also disappeared because of agricultural intensification, and their transformation into specialized vineyards; this dynamic, $94 \%$ of which is due to the planting of new vineyards, is mainly in the areas at the foot of the hills.

Deforestation and extensification are limited to small scattered areas. However, new plantations of contoured vineyards should be pointed out, of slightly less than 20 hectares, on lands that in 1960 were covered by broadleaved woodlands. Most of the landscape is unchanged, with the best preserved part of the historical landscape being the central belt of the study area, where traditional viticulture continues to be remunerative because high quality wines are produced and it is served by a good network of roads, and where the morphology of the land makes the substitution of traditional terraced vineyards with more mechanized longitudinal rows impossible.

Table 12. Cross tabulation of the evolutionary dynamics during the period 1960-2007 (Valdobbiadene study area).

Land uses 2007

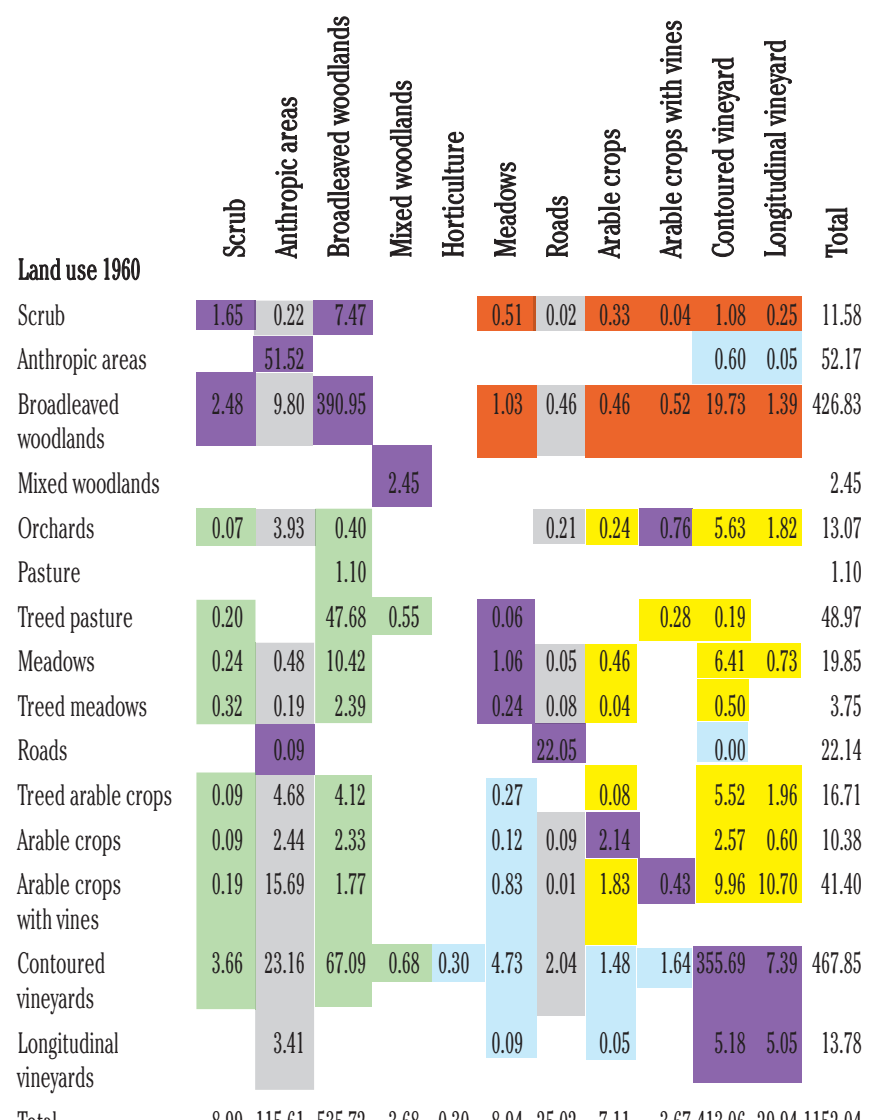

Total

\section{Earth terracing}

The studied territory has a morphology dominated by low but particularly steep hills. Vines have been cultivated for centuries on narrow terraces supported by earth embankments, not the more usual drystone walls, which allow otherwise unproductive lands to be cultivated.

The terraces are still today generally in very good condition (Figures 32 and 33), as the production of high-quality wines provides sufficient income to motivate non-mechanized cultivation and renders the main-

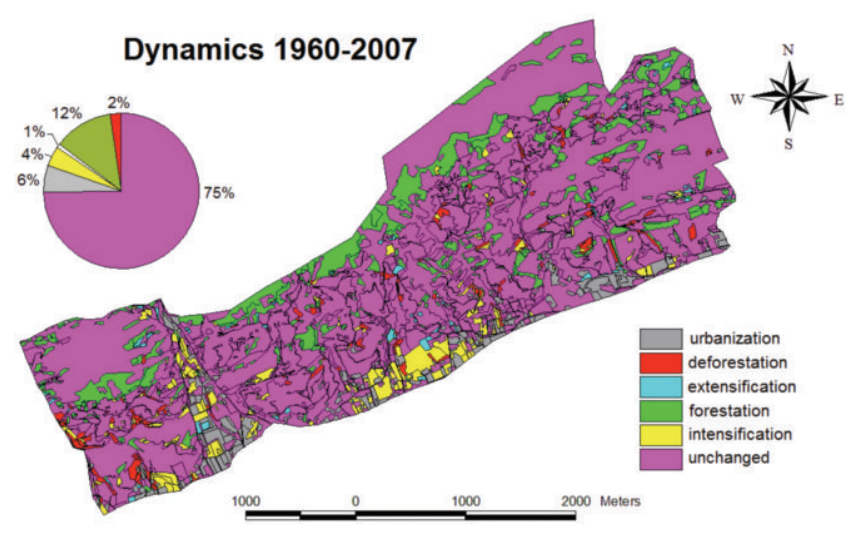

Figure 31. Map and percentages of the principal evolutionary dynamics for the period 1960-2007 (Valdobbiadene study area).

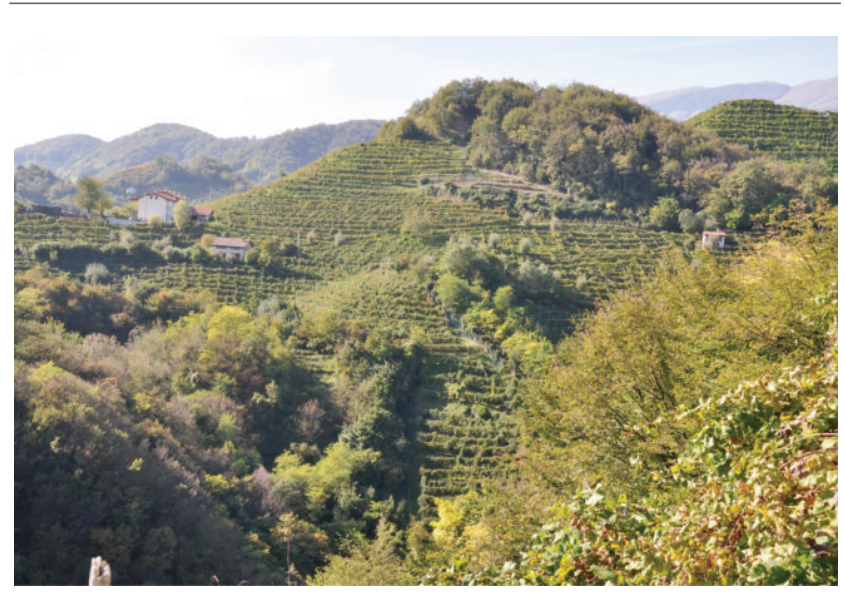

Figure 32. The terraced landscape of Valdobbiadene.

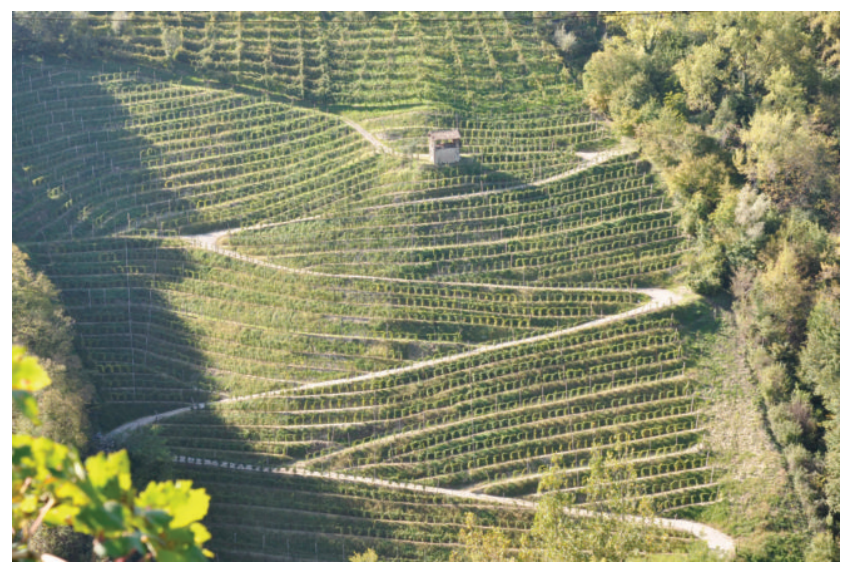

Figure 33. The dense network of earth terraces (Valdobbiadene study area). 
tenance of the terraces economically sustainable (Table 13). Also, because of the steeply sloping hills, it is not possible to convert the traditional contoured layout with more easily mechanized layouts, as has instead happened in many parts of the country. This conversion has only occurred on fairly limited areas closer to the plain. An overall reduction of $20 \%$ of the cultivated terraced land is reported, a value that in reality is not as high as it might seem, because the 2007 orthophotos do not show abandoned terraces invaded by shrubs or wasteland.

It can therefore be affirmed that as long as the wines produced locally command a huge and remunerative market, traditional wine-growing will not be abandoned, and the local landscape will continue to maintain its unique characteristics.

Indexes of landscape ecology

The indexes of landscape ecology highlight that, despite some changes in the landscape structure and land uses, the principal characteristics of the landscape are still on the whole unaltered (Table 14). The number of land uses diminishes significantly and the landscape is characterized by a greater equilibrium between the different types of land use, so presents a more simplified structure in terms of diversification, while the fragmentation level of the mosaic remains more or less unaltered. Figure 34, related to Sharpe's Index, shows a notable expansion of broadleaved woodlands and anthropic areas, which corresponds to a reduction in open areas (meadows and pastures, treed and not) and inter-cropping, in particular the inter-cropping of arable crops and vines that covered more than 40 hectares in 1960, and of which around 20 have been transformed into vineyards and other 16 have been lost to advancing urban areas, with the result that nowadays only 3 hectares of this land use survive.

Table 13. General situation of the Prosecco di Conegliano Valdobbiadene for 2008. Source: Consorzio della Tutela del Prosecco di Conegliano Valdobbiadene. ${ }^{\circ}$ The data of the estimate are obtained from market surveys (Boatto et al., 2008).

\begin{tabular}{lr}
\hline DOC recognition & 1969 \\
Communes involved & 15 \\
\hline Surface area listed in the Vineyard Register (Ha) & 4908 \\
Surface area registered as Superiore di Cartizze & 106.4 \\
\hline Employment in the sector & \\
no. Vine-growers & 2913 \\
no. Winemakers & 454 \\
no. Oenologists & 250 \\
no. Workers in the wine sector & 1500 \\
Spumante wineries & 166 \\
\hline Characteristics of the vintage & \\
Total bottles produced & $57,434,000$ \\
Bottles of sparkling wine produced & $48,058,000$ \\
\% of sparkling wine of the total bottles produced & 83.7 \\
Bottles of sparkling Superiore di Cartizze & $1,450,000$ \\
Bottles fizzy type produced & $7,504,000$ \\
Bottles still type produced & 421,000 \\
Market value of the product &
\end{tabular}

Table 14. Indices of landscape ecology.

\begin{tabular}{lcc} 
Valdobbiadene & 1960 & 2007 \\
Number patches & 904 & 943 \\
Average area patch (ha) & 1.27 & 1.22 \\
\hline Number land uses & 15 & 11 \\
Shannon's Index of Dominance & 1.14 & 1.12 \\
\hline Hill's diversity number & 4.79 & 3.59 \\
\hline
\end{tabular}

The vineyard situation is particularly interesting; Sharpe's Index demonstrates that the traditional contour-planted vineyards have had a consistent reduction, in part corresponding to an expansion of the vineyards with longitudinal rows. Even if the Valdobbiadene landscape is still on average intact, it should not be forgotten that processes of intensification are underway in the viticulture sector, which lead to a substitution, at least on gently sloping land, of the traditional contoured layout with the more easily mechanized and profitable longitudinal layout, with a consequent and important modification of the traditional landscape systems.

According to the Historical Index (Figure 35), inter-cropping is the land use type at greatest risk of disappearance from the local landscape. These different crop associations confer high diversity on the area and are an important testimony to traditional farming systems, but are now extremely scarce, with less than 4 hectares, against the approximately 72 hectares identified in 1960 .

The second land use in order of Historical Index value are the meadows and pastures, still present today despite their strong regression due to the abandoning of livestock grazing. These are an important land use, not only for their landscape or historical-cultural role, but also because they constitute an environment with a rich floral and faunal biodiversity.

The contour-planted vineyards have seen a reduction in surface area, even if they are still widespread and typical of the hills between Tarzo and Valdobbiadene, while the vineyards with longitudinal rows have an index value of less than one, confirming their expansion since 1960. The spread of longitudinal vineyards (that pass from 13.7 to around 30 hectares), accompanied by the increase in average size (from 0.5 to 1.1 hectares) and maximum size (from 3.5 to 12



Figure 34. Sharpe's index for the period 1960-2007 (Valdobbiadene study area).

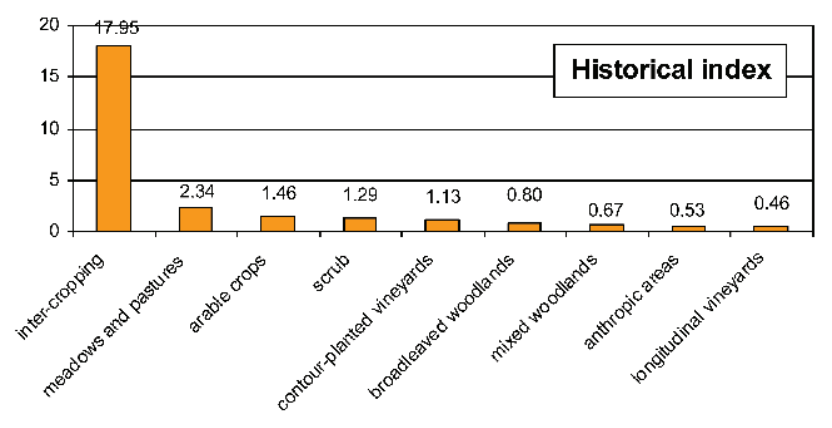

Figure 35. Historical index values for the different land uses (Valdobbiadene study area). 
hectares), indicates a marked trend towards homogenization of the viticultural landscape, especially in the flatter areas.

The map of the Historical Index (Figure 36) shows that the central part of the study area is where the main historical emergency is concentrated, linked to the vineyards traditionally laid out following the contours. In reality their disappearance does not appear likely; the majority of these lands have very steep slopes, where vineyards with longitudinal rows could not be planted, if not in a few small areas. Moreover, these vineyards produce high-quality wines, so viticulture, even if difficult to mechanize, is remunerative. On the other hand, it is also true that in the last fifty years around 55 hectares of contour-planted vineyards have been lost, in part colonized by woodland and in part transformed into longitudinal vineyards, so policies are necessary to encourage traditional viticulture and avoid further losses. The longitudinal vineyards are highlighted on the map, although the Historical Index value is less than one, in order to show the zones where there has been an intensification of viticulture, which as would be expected correspond to the plain areas at the foot of the densely terraced hills. The areas that assume higher Historical Index values, i.e. inter-cropping, meadows and pastures, and arable crops, form small scattered patches on the territory.

\section{Discussion of the results}

Although the study area has retained its principal characterizing element, i.e. contour-planted vineyards on terraces, there have also been degrading processes for the historical landscape that have led in fifty years to a simplification of the landscape mosaic, especially in the areas at higher altitude and those close to the plain.

The abandoning of pastures at higher altitudes has led to an expansion of woodland areas, and the loss of open spaces, which are important not only for the landscape but also for the conservation of biodiversity. The areas on the plain have instead been affected by urban expansion and the loss of inter-cropping, with a notable worsening of the landscape quality.

In the central altitudinal band the historical landscape has instead remained unaltered, for two reasons, one economic and one linked to the morphology. The wines produced in the Valdobbiadene area are of extremely high quality and have an international market, so, despite the high costs of cultivating the traditional vineyards, they guarantee the producers a sufficient income, even in such a technically complex situation. The second factor that has led to the continuation of vinegrowing in its traditional form is the steeply sloping land, which has impeded the substitution of the contour-planted vineyards with the more easily mechanized and remunerative longitudinal vineyards, limiting this process to the flatter lands. But if the market for the local wines should disappear, the incomes would no longer be sufficient to guarantee the cultivation of traditional vineyards, and their abandoning would become inevitable.

The historical landscape therefore remains highly intact, especially in relation to other similar situations. In these contexts the principal factor for the maintenance of cultivations that are labour-intensive and difficult to mechanize, is the presence of a flourishing market for the products.

\section{Conclusions}

The aim of the results reported above has been to establish that the efficacy of the rules that safeguard the maintenance of the characteristic elements of the landscape is strictly linked to the diversity and typicality of the landscape where they are applied and that the evaluation may only be conducted at local level. The process used to concisely evaluate the efficacy of the rules is based on a historical landscape analy-



Figura 36. Historical Index for the period 1960-2007. The longitudinal vineyards (IS $=0.46$ ) are highlighted in violet to demonstrate where there has been intensification of viticulture (Valdobbiadene study area).

sis conducted in some sample areas, which demonstrates that in the last 50 years (and with the arrival of the EU common agricultural policy) there has been a simplification and a homogenization of the landscape caused by the elimination of some of its typical elements.

From the analysis of the landscape dynamics, in addition to the elements mentioned in the discussions of the results of each study area, two other factors clearly emerge, common to all three situations studied. Firstly, the importance of the role of the socio-economic context, which must include a market for the local products, in maintaining the historical landscape. Indeed, this is much more vulnerable and compromised in contexts where no longer economically sustainable farming activities have been abandoned, as found for Costa Viola, but also in situations of strong intensification of the farming sector, with highquality products and a flourishing market, as happens in many highly specialized wine-growing areas. However, the element that appears to be most at risk in all three study cases is inter-cropping, which is not easily mechanized and is linked to traditional farming that doesn't aspire to product quantity, but which constitutes an important land use for the overall quality of the landscape.

The second factor emerging from the analysis regards the importance of terracing as a defence against surface erosion and landslides, especially on very steep slopes; in the Costa Viola area, with a reduction in the cultivation of the terraces and regular maintenance of the dry-stone walls, an increase in the number of landslides has been recorded (Nicolosi and Cambareri, 2007). The role of the terraces as a protection against surface erosion and landslides cannot be ignored, especially in a context, like Italy, where much of the rural territory is considered to be at hydrogeological risk.

In the case studies, the efficacy of the standard can be estimated through an evaluation of the reduction of the characteristic elements of the landscape by direct analysis, which takes into account the reduction in the density and intensity of the terracing, or in more extensive terms, where the reduction of the complexity of the landscape in general, including forestry aspects, is demonstrated by the reduction in the value of Hill's Diversity Number and by the increase in Shannon's Index of Dominance. The variation of the various indices applied to the study cases, which can only be evaluated through a historical analysis of the landscape and its evolutionary dynamics, represents in itself an index of efficacy of the standard.

The rules of cross compliance should therefore clearly express the necessity for a local evaluation of the characteristic elements of the landscape, using methods of historical landscape analysis to individu- 
ate the identifying elements. This allows the elements worth preserving to be precisely defined, so as to avoid the conservation, or as regards the agro-environmental measures the planning, of landscape elements discordant with the historical-cultural context. In fact, it cannot be presumed in the Regional Rural Development Plans that hedges and rows of trees are always positive for the landscape; this can only be established if a study, at local level, identifies them as important elements of the landscape identity. The local study of the landscape characteristics is also fundamental for territorial planning (Magnaghi, 2005). It is also lastly necessary to stress that the typical elements of a landscape are not only constituted by terracing, hedges, tree rows, etc., but also by particular types of landscape mosaics, artefacts, and diversified types of land use.

\section{References}

Agnoletti M., 2002. Il paesaggio agro-forestale toscano. Strumenti per l'analisi, la gestione e la conservazione. ARSIA ed., Firenze, Italy.

Agnoletti M., 2007. Il parco del paesaggio rurale appenninico di Moscheta. Pacini Ed., Ospedaletto, PI, Italy.

Agnoletti M., 2010. Paesaggi Rurali Storici. Per un catalogo nazionale. Laterza Ed., Bari, Italy.

Agnoletti M., Almanza R., Barbera G., La Mantia T., Nanni P., Paoletti S., Sisti A., Torquati B.M. 2006. Documento tematico sul paesaggio, Piano Strategico Nazionale di Sviluppo Rurale. Allegato a Architettura del Paesaggio, 15, CD Overview.
Baldeschi P., 2005. Il paesaggio agrario del Montalbano: identità sostenibilità società locale. Passigli Ed., Firenze, Italy.

Baudry J., Burel F., 1982. La mesure de la diversité spatiale. Relation avec la diversité specifique. Utilisation dans l'évaluations d'impact. Acta Oecol-Oec. Appl. 3:177-190.

Farina A., 2001. Ecologia del paesaggio. Principi, metodi e applicazioni. UTET Università Publ., Torino, Italy.

Ingegnoli V., 1993. Fondamenti di ecologia del paesaggio. Città Studi Ed., Torino, Italy.

Jenness J., 2006. Repeating shapes for ArcGIS. Available from:

http://www.jennessent.com/arcgis/repeat_shapes.htm. Accessed: 10 March 2006.

Magnaghi A., 2005. La rappresentazione identitaria del territorio. Alinea Ed., Firenze, Italy.

Mc Harg I., 2007. Progettare con la natura. Muzzio Ed., Padova, Italy.

Nicolosi A., Cambareri D., 2007. Il paesaggio terrazzato della Costa Viola. pp. 179-194 in $36^{\circ}$ Incontro di Studio Ce.S.E.T., Firenze University Press, Italy.

Romani V., 1994. Il paesaggio, teoria e pianificazione. Franco Angeli Ed., Milano, Italy.

Scaramellini G., Varotto M., 2008. Paesaggi terrazzati dell'arco alpino. Atlante. Progetto ALPTER, Marsilio, Venezia, Italy.

Vos W., Stortelder A., 1992. Vanishing Tuscan Landscape. PUDOC Publ., Wageningen, The Netherlands.

Zanchi B., Zanchi C., 2006. Le sistemazioni idraulico collinari quale fondamento della sostenibilità produttiva e della tutela paesaggistica ed ambientale. In V. Marinai (ed.) Paesaggio e sostenibilità: studi e progetti. ETS Ed., Pisa, Italy. 